CENTRE for ECONOMIC

$\begin{array}{lllllllllll}P & E & \mathrm{~F} & \mathrm{O} & \mathrm{R} & \mathrm{M} & \mathrm{A} & \mathrm{N} & \mathrm{C} & \mathrm{E}\end{array}$

CEP Discussion Paper No 1570

September 2018

The Economic Effects of Brexit - Evidence From the Stock Market

Holger Breinlich, Elsa Leromain

Dennis Novy, Thomas Sampson

Ahmed Usman 


\begin{abstract}
We study stock market reactions to the Brexit referendum on 23 June 2016 in order to assess investors' expectations about the effects of leaving the European Union on the UK economy. Our results suggest that initial stock price movements were driven by fears of a cyclical downturn and by the sterling depreciation following the referendum. We also find tentative evidence that market reactions to two subsequent speeches by Theresa May (her Conservative Party conference and Lancaster House speeches) were more closely correlated with potential changes to tariffs and non-tariff barriers on UKEU trade, indicating that investors may have updated their expectations in light of the possibility of a hard Brexit. We do not find a correlation between the share of EU migrants in different industries and stock market returns.
\end{abstract}

Key words: Brexit, depreciation, event study, recession, stock market, tariffs JEL Codes: F15; F23; G14

This paper was produced as part of the Centre's Trade Programme. The Centre for Economic Performance is financed by the Economic and Social Research Council.

We gratefully acknowledge financial support through ESRC Research Grant ES/R001804/1. We thank the editor and three referees for constructive comments.

Holger Breinlich, University of Surrey, CEPR and Centre for Economic Performance, London School of Economics. Elsa Leromain, Centre for Economic Performance, London School of Economics. Dennis Novy, University of Warwick, CEPR and Centre for Economic Performance, London School of Economics. Thomas Sampson, London School of Economics, Centre for Economic Performance, London School of Economics and CEPR. Ahmed Usman, CFCM, University of Nottingham.

Published by

Centre for Economic Performance

London School of Economics and Political Science

Houghton Street

London WC2A 2AE

All rights reserved. No part of this publication may be reproduced, stored in a retrieval system or transmitted in any form or by any means without the prior permission in writing of the publisher nor be issued to the public or circulated in any form other than that in which it is published.

Requests for permission to reproduce any article or part of the Working Paper should be sent to the editor at the above address.

(CH. Breinlich, E. Leromain, D. Novy, T. Sampson and A. Usman, submitted 2018. 


\section{Introduction}

On 23 June 2016, the UK electorate voted to leave the European Union. This decision is likely to be the most important change in UK economic policy for a generation. Most studies conducted prior to the referendum concluded that the long-run effect of a UK exit from the European Union ('Brexit') would be a reduction in British living standards (see for example, Dhingra et al. 2017; HM Treasury, 2016; OECD, 2016; NIESR, 2016). Because Brexit will not take place before March 2019, it is too early to evaluate the actual long-run impact on the UK economy. However, an increasing number of studies have documented that the referendum has already had negative short-term consequences such as lower GDP growth and higher inflation (see Born et al., 2017; Breinlich et al., 2017).

In this paper, we add to the emerging literature on the short-run effects of Brexit by studying stock market reactions to the referendum result and subsequent policy announcements that clarified the likely form Brexit would take - the speeches by the UK Prime Minister, Theresa May, at the Conservative Party conference in October 2016 and at Lancaster House in January 2017.

Besides providing direct evidence on share prices and the associated changes in stock market capitalisation and wealth, we hope that stock price reactions will also be useful to gauge the future economic impact of Brexit. Share prices are, in essence, aggregates of all information available to market participants at any given point in time. They reflect expectations about the future profitability of individual companies and sectors. Expected future changes in economic conditions such as changes in trade barriers post-Brexit will thus lead to immediate stock price reactions. Of course, market participants may be wrong, and share price movements might not correctly capture the effects of such changes. But given the information aggregation function of stock markets, share price reactions capture the 'consensus view' of a large number of wellinformed economic actors such as banks, insurance companies and investment funds. They are thus a useful alternative to estimates based on the work of individual experts, which form the basis of existing forecasts. Indeed, this is the motivation behind a large body of stock market event studies that use share price reactions to specific policy or regulatory events to infer likely future effects (see Binder, 1998, for a survey).

For each of our three events, we estimate abnormal returns for up to 350 UK-listed firms and regress these returns on indicators capturing exposure to the potential effects of a future exit from the European Union. Besides standard variables such as firm size and profitability, we use firms' export and import status, their engagement in EU and UK markets, and whether they report in currencies other than sterling. We also look at sector-level variables such as likely future EU tariff and non-tariff barriers, business cycle sensitivity, and the share of EU immigrants in the workforce of an industry.

We find that stock price changes on 24 June, the first trading day after the referendum, are best explained by variables capturing firms' dependence on the UK market, business cycle sensitivity, and firms' export status and reporting currency. We interpret these results as evidence that initial market reactions were driven by fears of an economic slowdown in the UK and by the consequences of the steep depreciation of sterling that followed the Leave vote. By 
contrast, prospective trade barriers do not have a significant impact, suggesting that market participants either did not have sufficient knowledge about such barriers or considered their imposition unlikely or unimportant.

This pattern is partially reversed when we look at reactions to Theresa May's speeches at the Conservative Party conference on 5 October 2016 and at Lancaster House on 17 January 2017. In our baseline specification, the only variable that has a consistently significant impact on 5 October 2016 are tariffs. In particular, firms in sectors with higher current EU import tariffs saw lower abnormal returns. We believe this is consistent with the idea that May's speech, as well as other policy announcements during the Conservative Party conference, was the first official confirmation that the UK would be aiming for an exit from both the EU customs union and the single market (a so-called 'hard Brexit'). The Lancaster House speech confirmed these intentions and provided additional detail, as well as clarifying that the UK was prepared to fall back on WTO trading terms in the event of a breakdown of negotiations with the EU. Results are less clear-cut for this event, but we also find negative coefficients on both tariff and non-tariff barriers in our abnormal returns regressions. Compared to our results for the day after the referendum, however, these additional findings appear somewhat less robust and are sensitive to the length of the event window chosen. By contrast, the explanatory power of our proxies for recessionary expectations and sterling's depreciation retain explanatory power over longer event windows beyond 24 June 2016.

Our work contributes to a growing literature on the observed effects of the Brexit vote on the UK economy. It is most closely related to three papers that also study stock market reactions to the referendum and subsequent events. Schiereck, Kiesel and Kolaric (2016) focus more narrowly on the financial sector, and show that stock prices of banks dropped sharply after the referendum, particularly for EU banks. Ramiah, Pham and Moosa (2016) look at a much wider range of sectors and discuss whether the observed price reactions are in line with prior expectations. They do not regress abnormal returns on explanatory variables, however, and thus cannot formally test hypotheses about differential sector-level impacts advanced in the pre-referendum literature. Similar to our paper, Davies and Studnicka (2017) correlate abnormal returns with a number of explanatory variables, focusing on the role of global value chains. We study a wider range of determinants, however, and link our choice of explanatory variables more closely to forecasts made before the referendum. This makes our results more relevant for a comparison of expert forecasts with the expectations of market participants. For example, we show that investors shared concerns regarding the potential for an economic downturn stressed by pre-referendum forecasts as well as (to a lesser extent) the importance of future trade barriers.

The present paper is also related to a small number of studies which look at stock price reactions to trade policy events. Hartigan, Kamma and Perry (1986, 1989), Hughes, Lenway and Rayburn (1997), Bloningen, Tomlin and Wilson (2004), and Crowley and Song (2014) look at stock price reactions to sector-specific anti-dumping duties. Grossman and Levinsohn (1989) use stock price reactions to test the specific factors model of international trade. Moser and Rose (2014) estimate the impact of regional trade agreements on aggregate stock market indices, and Brander (1991), Thompson (1993) and Breinlich (2014) follow stock price movements sur- 
rounding the ratification process of the US-Canada Free Trade Agreement of 1989. Our paper differs from these studies in that we look at stock market reactions to an arguably much more significant policy change that is expected to have strong effects beyond its direct implications for trade policy. In contrast to the literature on free trade agreements, Brexit also presents an interesting policy experiment in that it is expected to increase, rather than lower, future trade barriers.

The rest of this paper is structured as follows. Section 2 outlines the mechanisms through which Brexit may affect stock prices. Section 3 discusses the stock market event study methodology we use. Section 4 describes the specific events as well as our explanatory variables and data sources in more detail. Section 5 presents results for our abnormal returns regressions and carries out a number of robustness checks. Section 6 concludes.

\section{Economic Mechanisms}

The stock market response to the Brexit referendum 'shock' is expected to be greater for firms that are more exposed to the shock and its consequences. The shock has several different dimensions. First, the referendum result led to an immediate depreciation of sterling. On 24 June 2016 the pound depreciated by $8.1 \%$ against the US dollar and $5.8 \%$ against the euro. Second, leaving the EU could lead to major changes in future trade and migration policy. Third, the Leave vote increased uncertainty about UK economic policy and may have caused investors to downgrade their expectations for future UK growth in both the short-run and over longer horizons.

The impact of the depreciation of sterling depends on firms' participation in international markets. Multinational firms that earn revenue in currencies other than sterling will experience a direct increase in their sterling-denominated earnings following the depreciation. This is likely to raise their market value, since we study stock prices quoted in sterling. The depreciation may also boost exporters' profits in foreign markets through increased competitiveness and higher markups, while negatively affecting importers by increasing the cost of foreign goods.

Once the UK leaves the EU, it may no longer be a member of the EU's single market or customs union. Instead, it might sign a free trade agreement with the EU or it could trade with the EU under World Trade Organization (WTO) rules. Trading on WTO terms would lead to higher tariffs between the UK and the EU. Brexit is also likely to increase border non-tariff barriers such as customs procedures and rules of origin requirements. These barriers would be particularly costly for firms with complex international supply chains. To the extent that there is regulatory divergence between the UK and the EU after Brexit, exporters will also face additional costs of complying with EU product standards. Overall, exposure to future changes in UK-EU trade barriers is higher for firms that participate in international trade through either exporting or importing, for multinational firms with affiliates in EU countries and for firms in sectors where the EU currently has high tariff or non-tariff barriers on trade with WTO members.

Since high levels of EU immigration were arguably an important driver of the Leave vote, it is possible that the UK will impose tighter restrictions on EU immigration after Brexit. 
Consequently, firms employing a high share of EU immigrants may be more affected by the Leave vote, as they could suffer from a reduction in labor supply.

Before the referendum a majority of forecasters predicted a slowdown in economic growth or even a recession in the event of a Leave victory. Thus, firms in sectors that are less 'recessionproof' may be expected to suffer more in the aftermath of the referendum. Since the likelihood of a slowdown or a recession depends on investors' expectations about the form Brexit will take, the impact of policy announcements such as Theresa May's speeches at the Conservative Party conference and at Lancaster House could also depend on firms' business cycle sensitivities.

Finally, exposure to Brexit may also be related to firm characteristics such as performance and size. Larger and more profitable firms might be more resilient and better able to withstand any negative effects of Brexit. However, such firms are also likely to be more engaged in the international economy through trade or foreign investment. Consequently, the overall correlation of these characteristics with exposure to Brexit is ambiguous.

The next two sections describe how we test the importance of these mechanisms in explaining stock price responses to the Brexit vote. We first explain the methodology used for estimating abnormal stock returns and then discuss the variables employed to capture the different channels outlined above.

\section{Methodology}

We follow a two-step procedure to estimate the impact of a number of Brexit-related variables on the abnormal returns of UK-listed firms. First, we estimate a model of 'normal' stock returns which adjusts for differences in risk and other characteristics of stocks. A standard approach in the literature is to use the so-called market model which relates the return $r_{i t}$ on stock $i$ at time $t$ to a stock-specific constant $\alpha_{i}$ and the return on the market portfolio, $R_{m t}$ (Campbell et al., 1989; Binder, 1998):

$$
r_{i t}=\alpha_{i}+\beta_{i} R_{m t}+e_{i t}, \quad t \in T_{1}
$$

where $e_{i t}$ is the mean-zero random component of the return-generating process and $T_{1}$ is the socalled pre-event window of stock price data on which (1) is estimated. This method controls for differences in average returns across stocks $\left(\alpha_{i}\right)$, a stock's (non-diversifiable) risk as measured by $\beta_{i}$ and movements in the market portfolio. On event dates, stock returns also have an 'abnormal' component $\left(\tau_{i t}\right)$ which in the present context could be caused by the arrival of unexpected news about Brexit and its effects on the UK economy. Thus, on event dates stock returns are given by:

$$
r_{i t}=\alpha_{i}+\beta_{i} R_{m t}+\tau_{i t}+e_{i t}, \quad t \in T_{2} .
$$

where $T_{2}$ denotes the event window (for example, 24 June 2016 for our referendum event). Having obtained estimates of $\alpha_{i}$ and $\beta_{i}$ using stock price data from the pre-event window only, we compute abnormal returns estimates $\left(\hat{\tau}_{i t}\right)$ as a prediction error for the event window: 


$$
\hat{\tau}_{i t}=r_{i t}-\hat{r}_{i t}=r_{i t}-\hat{\alpha}_{i}-\hat{\beta}_{i} R_{m t}, \quad t \in T_{2},
$$

where the predicted values, $\hat{r}_{i t}=\hat{\alpha}_{i}+\hat{\beta}_{i} R_{m t}$, have been constructed using the pre-event window estimates of $\alpha_{i}$ and $\beta_{i}$ and the return on the market portfolio on the event day.

The second step is to model abnormal returns as a function of variables that explain variation in abnormal returns across firms and sectors.

$$
\tau_{i t}=\kappa+X_{i} \gamma+Z_{j} \delta+\mu_{i t}, \quad t \in T_{2}
$$

where $\tau_{i t}$ denotes the true abnormal return of firm $i$ on event date $t, \kappa$ is the regression constant, $X_{i}$ is a $N \times k_{1}$ vector of $k_{1}$ firm-level regressors and $Z_{j}$ is an $N \times k_{2}$ vector of $k_{2}$ sector-level regressors where $j$ denotes firm $i$ 's industry. ( $N$ denotes the number of stocks included in the regression.) We are interested in the signs and magnitudes of two coefficient vectors, $\gamma$ and $\delta$, which describe the correlation between our regressors and firm-level abnormal returns. ${ }^{1}$

An important issue for inference in event studies is the correct computation of standard errors for the coefficient estimates of interest $(\gamma$ and $\delta)$. To get a clearer understanding of the issues at stake, note from (2) and (3) that the relationship between the true abnormal return $\left(\tau_{i t}\right)$ and the estimated abnormal return $\left(\hat{\tau}_{i t}\right)$ is given by:

$$
\hat{\tau}_{i t}=\tau_{i t}+\left(\alpha_{i}-\hat{\alpha}_{i}\right)+\left(\beta_{i}-\hat{\beta}_{i}\right) R_{m t}+e_{i t}=\tau_{i t}+\eta_{i t}, \quad t \in T_{2}
$$

where $\eta_{i t}=\left(\alpha_{i}-\hat{\alpha}_{i}\right)+\left(\beta_{i}-\hat{\beta}_{i}\right) R_{m t}+e_{i t}$. Furthermore, recall that we have assumed that abnormal returns are a function of observables and a mean-zero random component $(\mu)$ as given by (4). Combining this expression with (5) allows us to state our basic estimating equation as follows:

$$
\hat{\tau}_{i t}=\tau_{i t}+\eta_{i t}=\kappa+X_{i} \gamma+Z_{j} \delta+\mu_{i t}+\eta_{i t}=\kappa+X_{i} \gamma+Z_{j} \delta+\varepsilon_{i t},
$$

where $\varepsilon_{i t}=\mu_{i t}+\eta_{i t}$. This expression shows that heteroskedasticity and cross-sectional dependence of the residuals in regressions using estimated abnormal returns as the dependent variable can arise from a number of sources. First, there could be heteroskedasticity and/or cross-sectional dependence in the random component of the abnormal returns themselves $\left(\mu_{i t}\right)$. Second, heteroskedasticity and/or cross-sectional dependence in the random component of the return-generating process $\left(e_{i t}\right)$ could be present. Finally, the forecasting error, $\left(\alpha_{i}-\hat{\alpha}_{i}\right)+$ $\left(\beta_{i}-\hat{\beta}_{i}\right) R_{m t}$, might introduce both heteroskedasticity and dependence; this source of error will become smaller as the length of the event period increases, however.

Karafiath (1994) and Harrington and Shrider (2007) carry out Monte Carlo simulations

\footnotetext{
${ }^{1}$ In principle, one could also directly use overall returns $\left(r_{i t}\right)$ as the dependent variable in the second-stage regression. We follow the standard practice in the event-study literature of using abnormal returns because we want to examine the part of a stock's return that is driven by the event in question, rather than other return patterns specific to the stock or its correlation with the market portfolio. If such stock-specific return patterns are correlated with our second-stage regressors, then using overall returns would bias our coefficient estimates. In practice, overall and abnormal returns are highly correlated (in excess of $95 \%$ on all three event dates) and, in our robustness checks below, we show that none of our qualitative findings is changed when using overall returns as the dependent variable.
} 
under different assumptions about the error terms $e_{i t}$ and $\mu_{i t}$ and find that simple OLS with heteroscedasticity robust standard errors performs well compared to other methods such as Feasible GLS. To account for possible cross-sectional dependence in $\varepsilon_{i t}$, we will also cluster standard errors by industry throughout this paper. ${ }^{2}$

\section{Events and Data Sources}

This section provides further information about the three events we will study, the choice of explanatory variables for our abnormal returns regressions and our data sources.

\subsection{Description of Events}

We analyse stock market reactions to three events. The first is the referendum on EU membership itself. While the referendum took place on 23 June 2016, the outcome was not known until the early hours of the next day and we use 24 June 2016 (a Friday) as our first event date. The referendum result took market participants by surprise. Opinion polls had predicted a close vote but betting markets implied a probability of around $85 \%$ that the UK would choose to remain in the EU (The Economist, 2016), reflecting the conventional wisdom that undecided voters would opt for the status quo. Once it became clear that the UK had voted to leave, the pound depreciated sharply against all major currencies and share prices dropped when markets reopened on 24 June. $^{3}$

Our second and third events centre on two speeches by Theresa May outlining the likely form Brexit would take. While the referendum determined that the UK would leave the EU, it remained unclear which of the many possible post-Brexit arrangements would be chosen. For example, would the UK continue to participate in the single market like Norway or form a customs union with the EU similar to Turkey? Our second and third events revealed information about the likely nature of future EU-UK relations which is why they represent useful additions to the analysis of post-referendum stock market reactions. Theresa May's speech at the Conservative Party conference on 5 October 2016 outlined her vision for a post-Brexit UK. Most observers deemed this vision incompatible with continued membership of the single market and possibly the customs union. For example, May promised restrictions on future EU immigration and an end to the European Court of Justice's jurisdiction in the UK, both of which are incompatible with integral parts of the single market. Theresa May's Lancaster House speech on 17 January 2017 provided the first detailed outline of the main objectives for the upcoming exit negotiations with the EU and stated explicitly that the UK would leave the single market and the customs union. It also clarified that the UK was prepared to fall back on WTO trading terms in the event of a breakdown of negotiations with the EU.

\footnotetext{
${ }^{2}$ See Cameron and Miller (2015) for further details as well as the relevant formula. In our data, firms are classified by our main data provider Bureau van Dijk into one of 150 NACE 4-digit industries. However, the number of industries actually included varies across regression samples and lies between 60 and 140 . See below for details.

${ }^{3}$ The FTSE All Shares declined by $3.8 \%$ on 24 June 2016. In our robustness checks, we will look at longer event windows to capture potential anticipation effects or delayed effects of the referendum.
} 
While both speeches represented a shift towards a 'hard Brexit', it is less clear to what extent they led to significant changes in market participants' expectations. In both cases, at least some of the information contained in the speeches had been made available to the public beforehand. Nevertheless, at least the Conservative Party conference speech seems to have caught investors unprepared (Financial Times, 2016) and it led to a further $4.3 \%$ depreciation of sterling against the US dollar in the week following 5 October. By contrast, there seems to have been a more concerted effort to prepare markets for the Lancaster House speech as information about some of its key points had been released a couple of days earlier. Sterling in fact rose by about $1.4 \%$ during the speech, presumably since investors valued greater certainty about the government's plans for Brexit (Financial Times, 2017). In order to capture potential anticipation effects, we will use longer event windows ( $t-1$ to $t+1$ and $t-3$ to $t+3$ ) for both the Conservative Party conference and the Lancaster House speeches as part of our robustness checks.

\subsection{Variables, Data Sources and Descriptive Statistics}

For the computation of abnormal returns, we require information on stock prices and market portfolio returns. Stock price information is taken from Datastream and information about market portfolio returns is obtained from the websites of the London Stock Exchange and the website investing.com. All returns in the paper are measured as percentage changes, implying that abnormal returns are measured in percentage changes as well. We use the FTSE All Share index as our market portfolio proxy in most specifications. However, we will also check the sensitivity of our results to using other proxies such as the MSCI Europe as well as to controlling for multiple market indices representing Asia, Europe and the US.

Regarding our regressors, we consider various sets of firm- and sector-specific variables $\left(X_{i}\right.$ and $Z_{j}$ in equation 6) as outlined below. These regressors are related to the economic mechanisms discussed in Section 2.

First, we use a firm's return on assets (ROA) and the value of its annual sales (in logs) as measures of profitability and size, respectively. We obtain data for both variables for the year before the referendum from Bureau van Dijk's Orbis database. The expected signs of these two regressors are a priori unclear. As explained in Section 2, on the one hand more profitable and larger firms might be better able to withstand negative shocks. But on the other hand, they might be more vulnerable as they tend to be more exposed internationally.

Second, we follow Davies and Studnicka (2017) in using information from Orbis on the share of a firm's subsidiaries in the UK and the rest of the EU, as well as the total count of subsidiaries. ${ }^{4}$ Davies and Studnicka interpret the share variables as measuring the exposure of a firm's global value chain (GVC) to future trade barriers brought about by Brexit. The count of subsidiaries is used as a proxy for the complexity of a firm's GVC, with more complex GVCs making a firm more vulnerable to the effects of leaving the EU. An alternative interpretation of the share of UK affiliates, however, is as a measure of exposure to the domestic UK market. In the light of Davies' and Studnicka's results, we expect all three variables to be negatively correlated with abnormal returns.

\footnotetext{
${ }^{4}$ Throughout this paper, we are using the terms "affiliate" and "subsidiary" interchangeably.
} 
Third, we use information on a firm's export and import status from Dun \& Bradstreet to construct three dummy variables for whether a firm is an exporter, an importer or an exporterimporter. ${ }^{5}$ While these indicators do not convey any information about the intensity with which firms trade, they are the best available proxies for firms' involvement in international trade. Given the steep depreciation of sterling on 24 June 2016, we would expect exporters to benefit from gaining competitiveness in foreign markets and importers to be negatively affected by the higher cost of foreign goods. Exchange rate effects were smaller and less immediate for the other two events, with the Lancaster House speech actually leading to a slight appreciation of the pound. Hence, the expected sign and significance patterns of the trade status dummies are less clear for these events.

Fourth, our final firm-level indicator is a dummy variable for whether a firm reports earnings in a currency other than sterling, again obtained from Orbis. This variable serves as a proxy for whether a firm earns a substantial amount of its profits in foreign currencies. If the pound depreciates, earnings measured in pounds will increase which will tend to push up the firm's FTSE All-Shares stock price (which is quoted in pounds). ${ }^{6}$

We also include four sector-level regressors. First, we compute the share of EU migrants in the workforce of an industry, using data from the UK Labour Force Survey published by the Office for National Statistics. ${ }^{7}$ As explained in Section 2, given that high levels of EU immigration were arguably a key driver of the Leave vote, it is likely that the UK will see tighter restrictions on EU immigration after Brexit. Hence, we may expect sectors with a higher share of EU migrants to see stronger negative abnormal returns. This should be true for the reaction to the referendum result itself, as well as for the two speeches which explicitly mentioned future restrictions on EU immigration.

Second, we include a dummy variable for industries that tend to outperform the market in recessions. We use the classification by Emsbo-Mattingly et al. (2017) who classify consumer staples, healthcare, telecommunication and utilities as 'recession outperformers'. ${ }^{8}$ Since a majority of forecasters predicted a growth slowdown or even a recession in the event of a Leave victory, we expect 'recession-proof' stocks to do better on 24 June 2016. ${ }^{9}$ By October 2016, however, it had become clear that the referendum result had not led to an immediate economic slowdown. For example, the UK was still the fastest growing economy in the G7 at the end of 2016 (OECD, 2018). Growth eventually slowed during 2017 (Born et al., 2017), but this was

\footnotetext{
${ }^{5}$ Dun \& Bradstreet provide information on whether the company is an exporter ("Yes or No") or importer ("Yes or No") and we create a dummy variable for export and import status of the company using this information. If a company is reported both as an exporter and importer, we classify that company as an exporter-importer. D\&B's sources include annual reports, Company House reports, industry reports and a network of 5,000 employees who check the accuracy of the data.

${ }^{6}$ We do not directly observe the geographic split of firm-level profits in our data. However, for a sub-sample of firms we have information on the distribution of sales based on subsidiary data. This information shows that firms reporting in a foreign currency do indeed earn a smaller share of revenues in pounds than firms reporting in GBP, and that this share is also small in absolute terms (on average only $25 \%$ of revenues come from inside the UK for firms reporting in a foreign currency).

${ }^{7}$ As is standard in the migration literature that uses this dataset, we focus on the country of birth of workers rather than their citizenship to define the share of EU migrants.

${ }^{8}$ See exhibits 6 and 7 in Emsbo-Mattingly et al. (2017).

${ }^{9}$ In the month immediately after the referendum, there was indeed a sharp deterioration of indicators of business confidence. For example, IHS Markit's Purchasing Manager Index (PMI) dropped from 52 in June to 47 in July 2016, a decrease of a magnitude last seen at the onset of the financial crisis in 2008.
} 
not yet evident at the time of the Lancaster House speech. Thus, we do not expect a significant correlation between the recession-proof dummy and abnormal returns for our last two events.

Finally, we include two measures of firms' exposure to future trade barriers between the UK and the EU. For goods-producing industries, we use the EU's most-favoured nation (MFN) tariffs, which are charged on imports from countries that do not have a preferential trade agreement with the EU. ${ }^{10}$ While the Lancaster House speech stressed that the UK would be seeking EU market access through a comprehensive free trade agreement, it also did not rule out the UK leaving the EU without an exit deal. In that case, the UK would have to fall back on trade governed by WTO rules. This would imply facing EU MFN tariffs as well as, in all likelihood, imposing such tariffs on imports from the EU. For services trade, future trade restrictions are harder to predict and would take the form of non-tariff barriers (NTBs). If the UK were to leave the single market, as implied by May's Conservative Party conference speech and explicitly stated in her Lancaster House speech, it would lose preferential access to EU services markets. Moreover, rules and regulations would likely diverge from the EU over time, leading to further increases in NTBs. Hence, we use the service trade restrictiveness index (STRI) developed by the World Bank to measure EU member countries' policies as applicable to non-EU providers. ${ }^{11}$

For both tariff and non-tariff barriers, we use two types of procedures to map trade barriers to firms. First, we calculate an average across all the industries a firm is reported to be active in; second, we use a narrower measure that only uses tariffs and NTBs for a firm's core industry as reported in Orbis. We use the wider measure in our baseline specification because it yields a significantly higher number of observations. The narrower measure is included as part of our robustness checks.

We start with data for all 636 companies in the FTSE All Shares at the time of our data download (October 2017). We use the FTSE All Shares because it provides a broad-based sample including firms with substantial international activities as well as more domestically focused companies. We drop eight companies that only report data for the financial year 2016 and with a closing date after the referendum. ${ }^{12}$ We discard a further 26 firms that do not report financial information at all in Orbis. For the estimation of the market model parameters in (1) we require one year of pre-event stock price data, which leads us to drop another 26 companies with short stock price time series. A substantial share (32\%) of the remaining companies are investment trusts. ${ }^{13}$ We exclude them from our baseline regressions because, in principle, they can invest anywhere in the world and it is unclear what effect Brexit would have on them. There is of course also a problem of double-counting for cases where investment trusts invest

\footnotetext{
${ }^{10}$ We use ad-valorem equivalent tariff rates for 2015, which is the most recent year available in the World Bank's WITS database (our data source).

${ }^{11}$ Data are for the year 2008, the only year available in the STRI. The STRI tries to measure the effect of EU regulations that discriminate against foreign services or service providers.

${ }^{12}$ We only use financial information for the year before the referendum because the Leave vote itself may have directly affected firms' financial outcomes.

${ }^{13}$ Investment trusts are collective investments where investors' money is pooled together from the sale of a fixed number of shares which a trust issues when it launches. This money is then invested in a similar fashion to open-ended investment funds and in a variety of assets, such as listed equities, government and corporate bonds or real estate from any region in the world.
} 
in other companies listed on the FTSE All Shares index. ${ }^{14}$ Finally, missing values for some of the regressors used in our analysis reduce the sample further, leaving us with around 350 stocks for our baseline regression. In addition to this baseline sample, we also consider a subsample of firms in goods-producing industries (for which we observe EU MFN tariffs) and a subsample of service-producing firms for which we have data on EU NTBs as measured by the STRI.

Table 1 presents descriptive statistics for the independent variables just discussed. Tables 2-4 show raw and abnormal returns on our three main event dates for the companies with the ten highest and ten lowest raw returns. On 24 June 2016, companies from the construction and related sectors accounted for 6 out of the 10 worst-performing stocks while precious metal producers and other mining companies dominate among the 10 best performers. This provides some first evidence that investors seem to have dumped business cycle sensitive shares on 24 June 2016 in favour of 'safe-haven' stocks such as gold producers like Acacia Mining or Randgold Resources. By contrast, no clear pattern is evident on the other two event dates. Finally, note that both average returns and abnormal returns were strongly negative on the day after the referendum but not on 5 October 2016 nor on 17 January 2017. This is consistent with our prior that the two later events led to less significant changes in market participants' expectations.

\section{Results}

\subsection{Baseline Results}

Table 5 shows our baseline results. Columns 1 to 3 look at abnormal returns on 24 June 2016, the first trading day following the referendum, and columns 4-9 examine abnormal return patterns on our other two event dates.

In column 1, we exclude our two trade barrier measures, allowing us to use the largest possible sample (352 stocks). As seen, most but not all coefficient signs confirm our prior expectations. Firms reporting in currencies other than sterling experienced additional positive abnormal returns of around 3.6 percentage points. By contrast, increasing the share of subsidiaries in the UK or the EU by 10 percentage points reduces abnormal returns by 0.9 percentage points and 0.4 percentage points, respectively. Contrary to the results reported in Davies and Studnicka (2017), however, the latter effect is not statistically significant. ${ }^{15}$ Our recession-proof dummy is also positive and significant as expected, indicating that stocks in industries which perform better during downturns experienced abnormal returns that were 3.6 percentage points higher. Finally, the trade status indicators broadly conform to our priors; export status is associated with higher and import status with lower abnormal returns, and exporter-importers saw abnormal returns of an additional 2.24 percentage points. With the exception of import status, all trade indicators are statistically significant at the $5 \%$ level.

The remaining regressors are all statistically insignificant. Contrary to Davies and Studnicka,

\footnotetext{
${ }^{14}$ As part of our robustness checks, we show that extending the sample to investment trusts does not qualitatively change our findings.

${ }^{15}$ The insignificance of the EU share variable seems to be driven by the inclusion of regressors not used by Davies and Studnicka (2017). After dropping the recession-proof and trade status dummies, as well as using $\log$ (assets) instead of $\log ($ sales) as in Davies and Studnicka (2017), the coefficient on the EU share regressor becomes significant at the $1 \%$ level.
} 
we do not find a significant effect of the total number of subsidiaries. ${ }^{16}$ Our proxies for size and profitability (ROA and log sales) are also insignificant, as is the share of EU migrants in an industry. ${ }^{17}$

Overall, abnormal return patterns on 24 June 2016 are mainly driven by the exchange rate devaluation and the fear of a possible economic slowdown or recession. The signs and significance patterns of the non-UK currency dummy and the trade status indicators are consistent with the expected impact of the sharp depreciation of the pound. The fact that stocks in 'recessionproof' industries did significantly better and that firms with more affiliates in the UK, and hence more exposure to the domestic market, did worse points to the additional role of recessionary expectations. Both sets of independent variables together explain around $34 \%$ of the total variation in abnormal returns on 24 June 2016. Adding the remaining regressors from Table 5 only increases this slightly to $37 \% .^{18}$

What role did expectations of higher trade barriers play in explaining abnormal return patterns? The results in columns 2 and 3, where we include tariff barriers for goods-producing industries and non-tariff barriers for selected service industries, respectively, suggest that such expectations did not matter as both trade barrier proxies are insignificant. We caution that sample sizes are of course considerably smaller in both regressions, explaining why some of the other indicators also become statistically insignificant. Interestingly, the share of affiliates in the EU becomes significantly negative in the goods-producing subsample regression (column 2), possibly suggesting that dependence on EU supply chains is more important for manufacturing firms. The only indicators that are consistently statistically significant across all three samples (columns 1-3) are the indicators we associate with expectations of a future recession (i.e., the recession-proof dummy and the share of affiliates in the UK).

Columns 4-6 and columns 7-9 in Table 5 examine abnormal return patterns on our other two event dates. As seen, the number of significant variables and the overall explanatory power of the regressors drop significantly, in line with our prior that these events only led to relatively minor changes in investor expectations. A number of interesting results emerge nevertheless.

First, the MFN tariff variable becomes significantly negative on 5 October 2016, consistent with Theresa May's Conservative party conference speech signalling the intent to pursue a hard Brexit. ${ }^{19}$ In terms of magnitudes, the coefficient estimate suggests that a one percentage point increase in future MFN tariffs is associated with 0.045 percentage points lower abnormal returns. Given that the average MFN tariff in our sample is 4.5 per cent, our results suggest that the expectation of higher tariffs was associated with negative abnormal returns of around

\footnotetext{
${ }^{16}$ Again, this seems to be due to the inclusion of additional control variables in our regressions. When we drop the recession-proof and trade status dummies, the coefficient on the number of affiliates decreases to -0.0052 and becomes statistically significant at the $5 \%$ level.

${ }^{17}$ Looking across columns in Table 5 , the impact of higher ROA is always negative but only statistically significant on two occasions. The coefficients on $\log$ (sales) and the EU immigrant share are less stable and sometimes switch signs.

${ }^{18}$ Using only the two recession proxies still yields an $\mathrm{R}^{2}$ of $26 \%$ and only using the exchange rate proxies an $\mathrm{R}^{2}$ of $20 \%$. By contrast, all the other regressors together only explain around $7 \%$ of the variation in abnormal returns.

${ }^{19}$ Inclusion of the MFN tariff variable also raises the explanatory power of the regression substantially from an $\mathrm{R}^{2}$ of $7.5 \%$ to an $\mathrm{R}^{2}$ of $13 \%$. In terms of $\mathrm{R}^{2}$ increases, it is the best explanatory variable for the goods-producing subsample on 5 October 2016.
} 
0.2 percentage points in the average industry. However, this average hides significant variation across sectors. For example, the MFN tariff at the 90th percentile of the distribution of tariffs across sectors is 15 per cent and the maximum tariff (for the dairies and cheese making industry) is 57 per cent, corresponding to abnormal return changes of 0.7 and 2.6 percentage points, respectively. ${ }^{20}$

Second, MFN tariffs are also associated with more negative abnormal returns on 17 January 2017, the day of Theresa May's Lancaster House speech, although the effect is smaller than in October and statistically insignificant. By contrast, the STRI variable proxying for non-tariff barriers in the service sector is now negative and statistically significant for the first time.

A final pattern that emerges on 17 January is that the two recession proxies (the recessionproof dummy and the share of affiliates in the UK) now have the opposite signs to the postreferendum day, although coefficient magnitudes are much smaller in absolute terms. It is not entirely clear how to interpret this result but it would be consistent with the generally positive market reactions to the Lancaster House speech mentioned above.

To conclude, the abnormal return patterns on 24 June are best interpreted as capturing the effects of the steep depreciation of sterling and fears of an imminent growth slowdown or recession. By contrast, future trade barriers and immigration shares across industries played no role in explaining abnormal returns. There is, however, some tentative evidence that share price reactions on 5 October and 17 January were at least in part due to expectations of higher future tariff and non-tariff barriers. ${ }^{21}$

\subsection{Robustness Checks}

Tables 6-12 present a number of robustness checks. We focus on what we consider the most important checks here and report additional results in a separate online appendix. ${ }^{22}$

Table 6 uses two alternative measures for the importance of UK and EU affiliates, focusing on the full sample of firms. Columns 1-3 use share data from Orbis based on the sales rather than the count of affiliates in the UK and the EU. Columns 4-6 use segment data from the annual accounts of parent companies which report the geographic breakdown of overall sales

\footnotetext{
${ }^{20}$ It is standard practice in the trade literature to break down overall tariff changes into import tariffs (payable by EU exporters to the UK), export tariffs (payable by UK exporters to the EU) and intermediate input tariffs (i.e., import tariffs leading to increases in the cost of domestic producers importing foreign intermediate inputs). Unfortunately, this decomposition is not feasible here. First, the most likely scenario is that the EU and the UK will impose the same MFN tariffs on each other in a WTO scenario. Second, we tried computing intermediate input tariffs using the UK's input-output matrix but given the level of aggregation available in UK IO tables, the resulting tariff was highly correlated with the MFN tariff (correlation coefficient of around 0.8). One case where the exclusion of intermediate input tariffs is clearly problematic is the sugar producer Tate \& Lyle who mainly use cane sugar and would benefit from a possible lowering of UK import tariffs after Brexit. Indeed, dropping Tate \& Lyle from our sample increases the MFN tariff coefficient to 0.05 .

${ }^{21}$ Note that, throughout, we are assuming that no firm-specific information is revealed on event dates that is systematically correlated with our regressors of interest. Unfortunately, we do not have detailed enough data on firm announcements to explicitly control for such potentially confounding factors.

${ }^{22}$ These additional robustness checks are: i) including investment trusts in our regression sample; ii) applying a narrower definition of our trade barrier measures by using only data for a firm's core industry rather than an average barrier across all industries a firm is active in; iii) including dummy variables for broad NACE 1-digit industry groups (Agriculture and Mining, Manufacturing, Utilities and Construction, Finance and Insurance, and Other Services); iv) using a different market portfolio proxy for the computation of abnormal returns (the MSCI Europe instead of the FTSE All Shares); and v) using a six-month instead of a one-year estimation period for the computation of abnormal returns.
} 
(also obtained from Orbis). Both variables are likely to be better proxies for the importance of the domestic and the EU market for UK-listed firms than share measures based on simple counts of affiliates. However, this comes at the cost of a substantial decrease in sample size. ${ }^{23}$ The results are qualitatively similar to Table 5 although the proxies for the sterling depreciation are less significant. ${ }^{24}$

In Tables 7 and 8, we examine the sensitivity of our results to different specifications of our first-stage market model estimation equation (1). In Table 7, we include three market indices in addition to the FTSE All Shares: the S\&P500, the MSCI Asia and the MSCI Europe. Ramiah et al. (2013) argue that this is necessary to control for the effects of asynchronicity, stock market integration and spillover effects in event studies. In Table 8, we allow for the possibility that our events led to persistent changes in systematic risk. Following Ramiah et al. (2013) and Breinlich (2014), we do so by interacting the market model equation's stock-specific intercepts and correlations with the market portfolio with dummy variables taking the value one after each of the events. ${ }^{25}$ Both modifications yield results that are very similar to our baseline estimates, consistent with the notion that for short event windows such as ours, the exact model used for the computation of abnormal returns is of lesser importance (see Andrade et al., 2001). ${ }^{26}$

In Table 9, we use overall instead of abnormal returns as the dependent variable in our regressions (i.e., $r_{i t}$ in the notation of Section 3). As we explained in Section 3, abnormal returns are our preferred dependent variable because they control for stock-specific return patterns that are unrelated to the event in question and might be correlated with our second-stage regressors. This said, returns on the market portfolio are likely to have been driven by the events in question to some extent, especially for our referendum event, so that we might not want to eliminate this part of overall returns. In practice, however, abnormal and overall returns are highly correlated in our sample. The correlation coefficient between the two returns is $97 \%$ on 24 June 2016, $99 \%$ on 5 October 2016 and $95 \%$ on 17 January. Not surprisingly then, the results presented in Table 9 are very similar to our baseline results.

Tables 10-12 explore the effect of varying the length of our event windows. In Table 10, we add the trading day before and after the event in question and use cumulative abnormal returns over these three-day windows as our dependent variable. This does not significantly affect coefficient patterns for the referendum event (now 23-27 June 2016 as no trading took place on the 25th and 26th). Significance levels are reduced for the other two events although

\footnotetext{
${ }^{23}$ See the Appendix for details on how we compute these two alternative measures.

${ }^{24}$ We do not report results for the goods-producing and services subsamples because the number of observations drops to as few as 50. Coefficient estimates on the MFN tariff and STRI variables are almost identical to before, although significance levels drop. Depending on the specification, both remain significant at the 10 per cent level, however.

${ }^{25}$ That is, we now replace equation (1) with $r_{i t}=\alpha_{i}+\beta_{i} R_{m t}+\sum_{v} d_{\text {post }, v}\left(\alpha_{i}+\beta_{i} R_{m t}\right)+e_{i t}$, where $v$ denotes our three events and $d_{\text {post }, v}=1$ for dates on or after event $v$. Note that in order to be able to estimate this new equation, we need to extend our original estimation period to include and go beyond our event dates. In practice, we use data up to 31 May 2017.

${ }^{26}$ Note that allowing for persistent changes in systematic risk by augmenting the market model equation with additional interaction terms is not suitable for controlling for more short-term changes in risk premia. To see this, note that in the extreme, one might want to allow for event day-specific changes in market model parameters which would mean fitting observed returns perfectly, with no abnormal returns left to explain. Thus, we caution that our results might at least in part pick up short-term changes in firm-specific risk perceptions in addition to changes in the future profitability of individual companies.
} 
the coefficient on the MFN tariff variable is around $50 \%$ larger than before.

Table 11 uses time windows that are more specific to the events in question. As discussed, the Leave vote came as a clear surprise to market participants so that using a longer pre-event window does not seem appropriate. Instead, we extend our window to include an additional trading week after the event, so the window now runs from 23 June to 1 July. By this time, both the FTSE100 and the FTSE All Shares indices had regained their initial losses, so it is of interest to see whether our coefficient pattern remains the same over this longer event horizon.

For our two other events, it seems likely that at least some of the relevant information reached market participants before the actual speeches, so we extend our event window to include the entire trading week surrounding the event. This is sufficient to include other speeches at the Conservative Party conference as well as interviews given to prepare market participants ahead of the Lancaster House speech. ${ }^{27}$

For the referendum event, results for the longer event window are qualitatively similar to before. Our proxies for recession expectations remain highly statistically significant and coefficient estimates are larger in magnitude than for our baseline results. The same is true for the dummy variable indicating whether firms report in a currency other than pounds, although the effect for the goods-producing subsample is not statistically significant. Coefficient signs for for the trade status indicators are similar to before but statistical significance is again lower.

Turning to the other two event windows, results are less consistent with previous estimates. The signs on the two trade barrier variables are still negative for the Conservative Party conference speech event but no longer statistically significant; by contrast, the MFN tariff variable is positive (although insignificant) for the Lancaster House speech. ${ }^{28}$ This is surprising given that information about the likely form of Brexit had leaked in the days prior to the two speeches and casts doubt on whether market participants really based stock price valuations on likely future trade barriers. By contrast, one of our recession proxies (the share of subsidiaries in the UK) is now significantly negative across two out of three samples for our second event (5 October).

These results indicate that the correlation between prospective trade barriers and abnormal returns found earlier seems somewhat fragile and depends on the exact specification of the relevant event windows. By contrast, the results related to sterling's depreciation and investors' expectations of a slowdown or recession are robust to short extensions of our event window. As a final robustness check, we extend the event window for the referendum event yet further, to 20 and 60 trading days after 24 June 2016, respectively. This allows us to check how long-lasting the impact of the referendum on abnormal return patterns was. We note that these results need to be interpreted with more caution than those for our shorter event windows. This is because new stock-specific information that is unrelated to the Brexit referendum will become

\footnotetext{
${ }^{27}$ Two events of particular importance in this context were a brief speech by Theresa May on Sunday, October 2, and an interview of Philip Hammond, the Chancellor of the Exchequer, with the German newspaper Welt am Sonntag on the Sunday before the Lancaster House speech. Both events provided information about the content of the subsequent speeches. However, they were both more low-key than Theresa May's main speeches on 5 October and 17 January, and the main negative reaction in currency markets only occurred after the 5 October speech. This is why we focus on the dates of the main speeches in our baseline regressions.

${ }^{28}$ The inclusion of Tate \& Lyle again seems to strongly influence estimates for the MFN variable on 5 October 2016; as discussed previously, Tate \& Lyle would stand to gain from potentially lower intermediate input tariffs after Brexit (see footnote 12). Excluding Tate \& Lyle from the regression does indeed nearly double the coefficient on the tariff variable to -0.049 , a magnitude similar to our baseline regressions.
} 
available in the weeks and months after the event, making the interpretation of cumulative abnormal return patterns more difficult. That is, the longer the horizon, the harder it is to argue that abnormal returns are caused only (or at least mainly) by the event in question. In addition, specification choices for the abnormal returns estimation equation (e.g., whether or not additional market indices are included) become much more important over longer time horizons, creating additional sources of noise.

Looking at columns 1-3 of Table 12, we see that results are still broadly similar for cumulative abnormal returns over the 20 trading days after the referendum. The main difference to our baseline results is that the coefficients on our proxies for exchange rate effects (currency dummies, trade status indicators) are smaller and less significant than before. On the other hand, the coefficients on our proxies for recessionary expectations (recession-proof dummy, share of UK affiliates) have actually increased in size and significance. Cumulative abnormal returns over the 60 trading days after the referendum (columns 4-6) show somewhat weaker patterns than before. The regression $\mathrm{R}^{2}$ is now only around $15 \%$, compared to approximately $30 \%$ for the 20 -day horizon and $35 \%$ for our baseline regression. The proxies for exchange rate effects are now insignificant although interestingly, coefficient signs and magnitude are similar to before, suggesting that the lack of significance is mainly driven by increased noise. The recession-proof dummy is now also slightly smaller in magnitude and insignificant throughout, possibly reflecting the fact that by September 2016, it had become clear that initial fears of an immediate recession were unfounded. Nevertheless, the coefficient magnitudes and significance levels of the UK affiliate share variable are still very similar to our baseline results, indicating that investors continued to take a negative view of firms with high exposure to the domestic UK market almost three months after the referendum.

\section{Conclusions}

This paper studies stock market reactions to the result of the 2016 UK referendum on EU membership and two of the main subsequent policy announcements that clarified the likely form Brexit would take, Theresa May's Conservative Party conference speech on 5 October 2016 and her Lancaster House speech on 17 January 2017. Besides providing direct evidence on share prices movements, the purpose of this analysis is to use price reactions as a guide to the likely future economic impact of Brexit and the channels through which such effects might materialise. To this end, we correlated stock price reactions with indicators capturing different potential effects of Brexit, including short-run impacts linked to the depreciation of sterling and the possibility of a slowdown in economic activity, as well as measures of potential future tariff and non-tariff barriers.

Our results support the hypothesis that stock market participants expected an economic downturn or even a recession in the days after the referendum. Share price movements during this period were also affected by the depreciation of sterling. By contrast, we find little evidence for the importance of variation in EU migrant shares across industries or future trade barriers in explaining abnormal returns following the referendum result. When analysing market reactions to Theresa May's two speeches our proxies have less explanatory power, consistent with the idea 
that much of the content of the speeches was already known to investors. Nevertheless, there is some evidence that abnormal return patterns were at least partially explained by expectations about future tariff and non-tariff barriers on the days of the two speeches. This result is less robust, however, and depends on the length of the event window chosen.

While our analysis provides new insight into investors' expectations about the consequences of Brexit, real economic effects will take time to materialise and market participants may be wrong. Fears that the Leave vote would trigger an immediate recession were unfounded, but the UK's economic growth has slowed relative to other major economies since 2016 (Born et al. 2017). It is too soon to know how Brexit will affect firms that engage in cross-border trade or investment between the UK and the EU. Crucially, the impact will depend on the nature of UK-EU relations after Brexit, which, at the time of writing, remain undecided.

\section{References}

[1] Andrade, G., M. Mitchell and E. Stafford (2001), "New Evidence and Perspectives on Mergers," Journal of Economic Perspectives, 15, 103-120.

[2] Binder, J.J. (1998), "The Event Study Methodology since 1969," Review of Quantitative Finance and Accounting, 11, 111-137.

[3] Bloningen, B., K. Tomlin and W. Wilson (2004), "Tariff-Jumping FDI and Domestic Firms' Profits," Canadian Journal of Economics, 37(3), 656-677.

[4] Born, B., G. Müller, M. Schularick and Petr Sedlacek (2017), "The Economic Consequences of the Brexit Vote," CEPR Discussion Paper 12454.

[5] Brander, J.A. (1991), "Election Polls, Free Trade, and the Stock Market: Evidence from the 1988 Canadian General Election," Canadian Journal of Economics, 24, 827-843.

[6] Breinlich, H. (2014), "Heterogeneous Firm-Level Responses to Trade Liberalization: A Test Using Stock Price Reactions," Journal of International Economics, 93, 270-285.

[7] Breinlich, H., E. Leromain, D. Novy and T. Sampson (2017), "The Consequences of the Brexit Vote for UK Inflation and Living Standards: First Evidence", CEP Technical Report.

[8] Cameron, A. and D. Miller (2015), "A Practitioner's Guide to Cluster-Robust Inference", The Journal of Human Resources, 50(2), 317-372.

[9] Campbell, J., A. Lo and A. MacKinlay (1997), The Econometrics of Financial Markets, Princeton University Press.

[10] Crowley, M. and H. Song (2014), "Trade Policy Shocks and Stock Market Returns: Evidence from Chinese Solar Panels," mimeograph, University of Cambridge.

[11] Davies, R. and Z. Studnicka (2017), "The Heterogeneous Impact of Brexit: Early Indications from the FTSE," European Economic Review, forthcoming. 
[12] Dhingra, S., H. Huang, G. Ottaviano, J.P. Pessoa, T. Sampson and J. Van Reenen (2017), "The Costs and Benefits of Leaving the EU: Trade Effects," Economic Policy 32: 651-705.

[13] The Economist (2016), "Who Said Brexit was a Surprise?" June 24, 2016.

[14] Emsbo-Mattingly, L., D. Hofschire, A. Litvak, J. Lund-Wilde (2017), "The Business Cycle Approach to Equity Sector Investing," Fidelity Investment Leadership Series, January 2017.

[15] Financial Times (2016), "Theresa May: Pounding Home the Message," October 7, 2016.

[16] Financial Times (2017), "Theresa May Unveils Plan to Quit EU Single Market under Brexit," January 17, 2016.

[17] Grossman, G.M. and J.A. Levinsohn (1989), "Import Competition and the Stock Market Return to Capital," American Economic Review, 79(5), 1065-1087.

[18] Harrington, S. and D. Shrider (2007), "All Events Induce Variance: Analyzing Abnormal Returns When Effects Vary across Firms," The Journal of Financial and Quantitative Analysis, Vol. 42, No. 1 (March 2007), 229-256.

[19] Hartigan, J.C., Perry, P.R. and S. Kamma (1986), "The Value of Administered Protection: A Capital Market Approach," Review of Economics and Statistics, 68(4), 610-617.

[20] Hartigan, J.C., S. Kamma, and P.R. Perry (1989), "The Injury Determination Category and the Value of Relief from Dumping," Review of Economics and Statistics, 71, 183-186.

[21] HM Treasury (2016), "The Long-term Economic Impact of EU Membership and the Alternatives," HMSO.

[22] Hughes, J.S., S. Lenway, and J. Rayburn (1997), "Stock Price Effects of U.S. Trade Policy Responses to Japanese Trading Practices in Semi-Conductors," Canadian Journal of Economics, 30, 922-942.

[23] Karafiath, I. (1994), "On the Efficiency of Least Squares Regression with Security Abnormal Returns as the Dependent Variable," The Journal of Financial and Quantitative Analysis, Vol. 29, No. 2 (June 1994), 279-300.

[24] Moser, C. and A.K. Rose (2014), "Who Benefits from Regional Trade Agreements? The View from the Stock Market," European Economic Review, 68, 31-47.

[25] NIESR (2016), "The Economic Consequences of Leaving the EU," May Special Issue.

[26] OECD (2016), "The Economic Consequences of Brexit: A Taxing Decision," OECD (http://www.oecd.org/economy/the-economic-consequences-of-brexit-a-taxingdecision.htm).

[27] OECD (2018), OECD.Stat database. Accessed in February 2018.

[28] Ramiah, V., B. Martin and M. Moosa (2013), "How Does the Stock Market React to the Announcement of Green Policies?" Journal of Banking and Finance, 37, 1747-1758.

[29] Ramiah, V., H. Pham and I. Moosa (2016), "The Sectoral Effects of Brexit on the British Economy: Early Evidence from the Reaction of the Stock Market," Applied Economics, 49:26, 2508-2514.

[30] Schiereck, D., F. Kiesel and S. Kolaric (2016), "Brexit: (Not) Another Lehman Moment for Banks?," Finance Research Letters, 19, 291-297. 
[31] Thompson, A.J. (1993), "The Anticipated Sectoral Adjustment to the Canada - United States Free Trade Agreement: An Event Study Analysis," Canadian Journal of Economics, 26(2), 253-271. 


\section{A Construction of Alternative Sales Share Measures}

For our robustness check in Section 5.2 (Table 6), we use two methods to calculate the geographic sales distribution of the firms in our sample.

\section{A.1 Method 1 - Using Sales of Subsidiaries of the Parent Firm}

We start with the subsample of firms from Orbis that had complete information about their own sales (operating revenue) and the sales of their subsidiaries. Sales of each parent firm are the sum of the sales of all its subsidiaries including any sales of the parent firm itself. Accounting rules around the world (especially IFRS) require the parent firm to consolidate the financial statements of all its subsidiaries when the ownership of the parent firm is $50 \%$ or greater in its subsidiaries. ${ }^{29}$ Therefore, we only use data for subsidiaries in which the parent firm has at least a $50 \%$ ownership stake.

In principle, the sum of sales of all subsidiaries should be equal to the consolidated sales of the parent firm but this is not the case in Orbis. There are 126 firms for which the sum of sales of the subsidiaries exceeds the consolidated sales of the parent firm and we drop all such companies, leaving us with a final sample of 360 firms.

For these firms, we impute the sales of any subsidiary with missing sales data as follows. We subtract the sum of available sales of all subsidiaries from the consolidated sales of the parent firm and then divide the result by the total number of subsidiaries with missing sales data. To illustrate, assume that the consolidated sales of the UK parent firm are $£ 100$ million (excluding sales of the parent firm itself), that it has three subsidiaries and that sales information is only available for one subsidiary located in Germany (sales of $£ 50$ million). The sales data for the other two subsidiaries located in the United Kingdom and Spain are missing. Out imputation procedure attributes the remaining $£ 50$ million equally across these two subsidiaries.

Finally, to compute the share of total sales of the parent firm originating from Europe, we sum the sales of all subsidiaries located in Europe and divide it by the consolidated sales of the parent firm (using 2016 data). Similarly, we compute the share of total sales originating in the UK.

\section{A.2 Method 2 - Using the Geographic Breakdown of the Sales of Parent Firms}

Orbis also directly reports the geographical breakdown of firm sales. The level of aggregation used in the geographical breakdown is not homogenous, and information is sometimes for a region (not a country) or even multiple regions. We classify sales as originating from Europe if the geographic area of the sales of the parent firm is given as Europe only (or any of the countries in Europe). We also classify sales as originating from Europe if the geographic area of the sales of the parent firm is given as "Europe and Asia" (or "Europe and Africa" or "Germany and Ghana") instead of Europe alone. We adopt this approach because our aim is to calculate the dependence of the parent firm (in terms of its sales) on Europe. Not classifying "Europe and Africa" as sales originating from "Europe" will underestimate the dependence of the parent firm on Europe.

Finally, we consolidate the sales originating from each of Europe and the UK, and divide by total sales of the parent firm (using 2016 data) to calculate the sales shares. Missing data or unsuitable geographic breakdowns of sales made it impossible to calculate segment-based sales shares for the majority of firms in our sample, leaving us with information for only 181 firms.

\footnotetext{
${ }^{29}$ See http://stevecollings.co.uk/consolidated-accounts-in-the-uk-a-quick-guide/ (accessed 12/3/2018).
} 
Table 1: Descriptive Statistics

\begin{tabular}{|c|c|c|c|c|c|}
\hline Variable & Obs & Mean & Std. Dev. & Min & Max \\
\hline Log(assets) & 394 & 21.34 & 1.94 & 16.69 & 28.51 \\
\hline ROA & 393 & 0.05 & 0.10 & -0.68 & 0.47 \\
\hline Non-GBP Reporting Currency & 394 & 0.19 & 0.39 & 0.00 & 1.00 \\
\hline Share EU affiliates & 394 & 0.18 & 0.20 & 0.00 & 1.00 \\
\hline Share UK affiliates & 394 & 0.53 & 0.32 & 0.00 & 1.00 \\
\hline Log(number of affiliates) & 394 & 4.16 & 1.46 & 0.00 & 8.32 \\
\hline Log(sales) & 380 & 20.73 & 1.78 & 14.52 & 26.30 \\
\hline EU MFN (narrow) & 138 & 0.04 & 0.08 & 0.00 & 0.57 \\
\hline STRI (narrow) & 88 & 0.15 & 0.15 & 0.00 & 0.55 \\
\hline EU MFN (wide) & 143 & 0.05 & 0.08 & 0.00 & 0.57 \\
\hline STRI (wide) & 152 & 0.13 & 0.13 & 0.00 & 0.55 \\
\hline Share EU immigrants & 394 & 0.09 & 0.08 & 0.00 & 0.46 \\
\hline Recession-proof dummy & 394 & 0.15 & 0.35 & 0.00 & 1.00 \\
\hline Exporter & 366 & 0.29 & 0.46 & 0.00 & 1.00 \\
\hline Importer & 366 & 0.23 & 0.42 & 0.00 & 1.00 \\
\hline Exporter-Importer & 366 & 0.08 & 0.27 & 0.00 & 1.00 \\
\hline
\end{tabular}

Notes: Descriptive statistics are calculated over the baseline sample of firms, excluding Investment Trusts.

ROA, Non-GBP Reporting Currency, Share EU affiliates, Share UK affiliates, Log(number of affiliates), Log(sales), Exporter, Importer and Exporter-Importer are firm-level variables. EU MFN (narrow), STRI (narrow), EU MFN (wide), STRI (wide), Share of EU immigrants are sector-level variables. Log(assets) is the logarithm of the value of a firm's assets. ROA is a firm's return on assets. Non-GBP Reporting Currency is a dummy variable for whether a firm reports earnings in a currency other than sterling. EU MFN is the current EU most-favoured nation tariff applied to third countries for goods-producing industries, while STRI is the service trade restrictiveness index developed by the World Bank for services industries. "Recession-proof" is a dummy variable for industries that tend to outperform the market in recessions. Exporter, importer and exporter-importer are dummies for firms' trade status. Narrow and wide refer to the type of industry mapping methodology used. 
Table 2: Best and worst-performing stocks on 24 June 2016.

\begin{tabular}{|c|c|c|c|c|}
\hline Company Name & Industry (NACE 4-digit) & Return & $\begin{array}{l}\text { Abnormal } \\
\text { Return }\end{array}$ & T-Statistic \\
\hline \multicolumn{5}{|c|}{ Top 10 performers } \\
\hline RANDGOLD RESOURCES LIMITED & Precious metals production & $14.2 \%$ & $14.0 \%$ & 5.64 \\
\hline FRESNILLO PLC & Other mining and quarrying nec. & $11.9 \%$ & $14.1 \%$ & 5.96 \\
\hline CENTAMIN PLC & Mining of other non-ferrous metal ores & $10.5 \%$ & $11.3 \%$ & 3.88 \\
\hline SIRIUS MINERALS PLC & Mining of other non-ferrous metal ores & $5.6 \%$ & $8.1 \%$ & 1.55 \\
\hline NMC HEALTH PLC & Other human health activities & $5.0 \%$ & $7.4 \%$ & 3.39 \\
\hline COMPASS GROUP PLC & Restaurants and mobile food service activities & $3.9 \%$ & $6.6 \%$ & 6.69 \\
\hline HOGG ROBINSON GROUP PLC & Travel agency activities & $3.8 \%$ & $4.7 \%$ & 2.29 \\
\hline \multicolumn{5}{|c|}{ Bottom 10 performers } \\
\hline BELLWAY P L C & Construction of residential and non-residential buildings & $-24.5 \%$ & $-21.5 \%$ & -12.00 \\
\hline VIRGIN MONEY HOLDINGS (UK) PLC & Activities of holding companies & $-24.9 \%$ & $-21.0 \%$ & -12.57 \\
\hline CREST NICHOLSON HOLDINGS PLC & Manuf. of machinery for mining, quarrying and construction & $-26.5 \%$ & $-22.9 \%$ & -9.79 \\
\hline PERSIMMON PUBLIC LIMITED COMPANY & Construction of residential and non-residential buildings & $-27.6 \%$ & $-24.2 \%$ & -12.67 \\
\hline TAYLOR WIMPEY PLC & Construction of residential and non-residential buildings & $-29.3 \%$ & $-25.6 \%$ & -15.23 \\
\hline ALDERMORE GROUP PLC & Activities of holding companies & $-32.0 \%$ & $-28.7 \%$ & -15.71 \\
\hline Average across all companies in sample & & $-6.4 \%$ & $-3.5 \%$ & -11.14 \\
\hline
\end{tabular}

Notes: Table lists the best and worst performing stocks on 24 June 2016. We report each company's main sector of activity, overall stock return and the abnormal return and associated t-statistic (computed following Campbell et al., 1997). 
Table 3: Best and worst-performing stocks on 5 October 2016.

\begin{tabular}{|c|c|c|c|c|}
\hline Company Name & Industry (NACE 4-digit) & Return & $\begin{array}{c}\text { Abnormal } \\
\text { Return }\end{array}$ & T-Statistic \\
\hline \multicolumn{5}{|c|}{ Top 10 performers } \\
\hline TESCO PLC & Retail sales, non-specialised stores & $9.8 \%$ & $10.4 \%$ & 5.64 \\
\hline ALDERMORE GROUP PLC & Activities of holding companies & $6.9 \%$ & $7.5 \%$ & 2.91 \\
\hline RENOLD PUBLIC LIMITED COMPANY & Manufacture of bearings, gears, gearing and driving elements & $5.8 \%$ & $6.2 \%$ & 2.29 \\
\hline KENMARE RESOURCES PUBLIC LIMITED COMPANY & Other mining and quarrying nec & $5.1 \%$ & $5.8 \%$ & 0.80 \\
\hline CAMBIAN GROUP PLC & Other human health activities & $4.6 \%$ & $5.2 \%$ & 0.94 \\
\hline SPEEDY HIRE PLC & Renting/leasing of other machinery, equip. \& tangible goods nec & $3.9 \%$ & $4.4 \%$ & 1.28 \\
\hline JOHN MENZIES PLC & Non-specialised wholesale trade & $3.5 \%$ & $3.7 \%$ & 2.28 \\
\hline ELECTROCOMPONENTS PLC & Wholesale of electronic and telecomm. equipment and parts & $3.3 \%$ & $3.7 \%$ & 1.90 \\
\hline COATS GROUP PLC & Manufacture of other special-purpose machinery nec & $3.2 \%$ & $3.3 \%$ & 1.75 \\
\hline STV GROUP PLC & Television programming and broadcasting activities & $3.2 \%$ & $3.4 \%$ & 1.50 \\
\hline \multicolumn{5}{|c|}{ Bottom 10 performers } \\
\hline COUNTRYWIDE PLC & Real estate agencies & $-3.5 \%$ & $-3.0 \%$ & -1.51 \\
\hline CARCLO PLC & Manufacture of other outerwear & $-3.7 \%$ & $-3.5 \%$ & -1.20 \\
\hline RANDGOLD RESOURCES LIMITED & Precious metals production & $-4.0 \%$ & $-4.1 \%$ & -1.66 \\
\hline LSL PROPERTY SERVICES PLC & Real estate agencies & $-4.0 \%$ & $-3.8 \%$ & -1.99 \\
\hline UNITED UTILITIES GROUP PLC & Water collection, treatment and supply & $-4.4 \%$ & $-4.0 \%$ & -4.56 \\
\hline DEVRO PLC & Manufacture of other food products nec & $-4.7 \%$ & $-4.4 \%$ & -2.81 \\
\hline LOW \& BONAR PUBLIC LIMITED COMPANY & Manufacture of household \& sanitary goods \& toilet requisites & $-5.2 \%$ & $-4.9 \%$ & -2.60 \\
\hline POLYMETAL INTERNATIONAL PLC & Mining of other non-ferrous metal ores & $-5.7 \%$ & $-5.7 \%$ & -2.70 \\
\hline HOCHSCHILD MINING PLC & Precious metals production & $-6.1 \%$ & $-6.2 \%$ & -1.39 \\
\hline PAYPOINT PLC & Activities of collection agencies and credit bureaus & $-6.2 \%$ & $-6.0 \%$ & -3.70 \\
\hline TOPPS TILES PLC & Wholesale of wood, construction materials and sanitary equip. & $-8.7 \%$ & $-8.6 \%$ & -5.04 \\
\hline Average across all companies in sample & & $-0.4 \%$ & $0.0 \%$ & \\
\hline
\end{tabular}

Notes: Table lists the best and worst performing stocks on 24 June 2016. We report each company's main sector of activity, overall stock return and the abnormal return and associated t-statistic (computed following Campbell et al., 1997). 
Table 4: Best and worst-performing stocks on 17 January 2017.

\begin{tabular}{|c|c|c|c|c|}
\hline Company Name & Industry (NACE 4-digit) & Return & $\begin{array}{c}\text { Abnormal } \\
\text { Return }\end{array}$ & T-Statistic \\
\hline \multicolumn{5}{|c|}{ Top 10 performers } \\
\hline GAMES WORKSHOP GROUP PLC & Manufacture of games and toys & $6.3 \%$ & $6.4 \%$ & 3.53 \\
\hline ROLLS-ROYCE HOLDINGS PLC & Manufacture of air and spacecraft and related machinery & $4.4 \%$ & $6.1 \%$ & 2.89 \\
\hline DECHRA PHARMACEUTICALS PLC & Manufacture of pharmaceutical preparations & $4.1 \%$ & $4.5 \%$ & 3.08 \\
\hline INTERNATIONAL PERSONAL FINANCE PLC & Activities auxiliary to financial services, exc. insurance $\&$ pension & $3.7 \%$ & $5.2 \%$ & 1.87 \\
\hline PREMIER OIL PLC & Extraction of crude petroleum & $3.6 \%$ & $6.9 \%$ & 1.29 \\
\hline EASYJET PLC & Passenger air transport & $3.4 \%$ & $4.3 \%$ & 2.81 \\
\hline MORGAN ADVANCED MATERIALS PLC & Manufacture of other chemical products nec & $3.1 \%$ & $4.6 \%$ & 2.63 \\
\hline \multicolumn{5}{|c|}{ Bottom 10 performers } \\
\hline CARNIVAL PLC & Sea and coastal passenger water transport & $-3.5 \%$ & $-2.3 \%$ & -1.62 \\
\hline JIMMY CHOO PLC & Retail sale of footwear and leather goods in specialised stores & $-3.6 \%$ & $-2.6 \%$ & -1.05 \\
\hline VEDANTA RESOURCES PLC & Casting of other non-ferrous metals & $-3.8 \%$ & $-1.5 \%$ & -0.38 \\
\hline BRITISH AMERICAN TOBACCO P.L.C. & Manufacture of tobacco products & $-3.8 \%$ & $-2.9 \%$ & -3.78 \\
\hline FERREXPO PLC & Mining of iron ores & $-4.0 \%$ & $-2.4 \%$ & -0.40 \\
\hline GULF MARINE SERVICES PLC & Building of ships and floating structures & $-6.0 \%$ & $-5.2 \%$ & -1.83 \\
\hline HUNTSWORTH PLC & Market research and public opinion polling & $-7.3 \%$ & $-6.9 \%$ & -3.13 \\
\hline Average across all companies in sample & & $-0.2 \%$ & $0.7 \%$ & \\
\hline
\end{tabular}

Notes: Table lists the best and worst performing stocks on 24 June 2016. We report each company's main sector of activity, overall stock return and the abnormal return and associated t-statistic (computed following Campbell et al., 1997). 
Table 5: Baseline Results

\begin{tabular}{|c|c|c|c|c|c|c|c|c|c|}
\hline Date & 24 June 16 & 24 June 16 & 24 June 16 & 5 Oct 16 & 5 Oct 16 & 5 Oct 16 & 17 Jan 17 & 17 Jan 17 & 17 Jan 17 \\
\hline & (1) & (2) & (3) & (4) & (5) & (6) & (7) & (8) & (9) \\
\hline VARIABLES & $A R(t)$ & $A R(t)$ & $A R(t)$ & $A R(t)$ & $A R(t)$ & $A R(t)$ & $A R(t)$ & $A R(t)$ & $A R(t)$ \\
\hline \multirow[t]{2}{*}{ ROA } & -0.0568 & -0.0546 & -0.0508 & $-0.0292 * *$ & -0.0249 & $-0.0400 * *$ & -0.0141 & -0.0135 & -0.00457 \\
\hline & $(0.0344)$ & $(0.0443)$ & (0.0835) & $(0.0130)$ & (0.0167) & (0.0165) & (0.0100) & (0.0131) & (0.0205) \\
\hline \multirow[t]{2}{*}{ Log(sales) } & 0.00176 & $0.00802 * *$ & -0.000739 & 0.000986 & -0.000271 & $0.00257^{* *}$ & -0.000461 & -0.00205 & -0.000166 \\
\hline & $(0.00210)$ & $(0.00345)$ & $(0.00413)$ & $(0.000751)$ & $(0.00168)$ & $(0.00119)$ & $(0.000758)$ & (0.00129) & $(0.00132)$ \\
\hline \multirow[t]{2}{*}{ Non-GBP currency } & $0.0361 * * *$ & $0.0251^{* *}$ & 0.0301 & 0.00601 & 0.00417 & 0.00508 & 0.00123 & 0.00420 & 0.00337 \\
\hline & $(0.00809)$ & $(0.0115)$ & $(0.0212)$ & $(0.00375)$ & $(0.00603)$ & $(0.00465)$ & $(0.00290)$ & $(0.00531)$ & $(0.00550)$ \\
\hline \multirow[t]{2}{*}{ Share EU affiliates } & -0.0431 & $-0.0737 * * *$ & -0.0458 & -0.000184 & 0.00195 & -0.00210 & 0.00394 & -0.00328 & 0.0143 \\
\hline & $(0.0271)$ & $(0.0273)$ & $(0.0803)$ & $(0.00661)$ & $(0.0146)$ & $(0.0112)$ & $(0.00629)$ & $(0.0110)$ & (0.0120) \\
\hline \multirow[t]{2}{*}{ Share UK affiliates } & $-0.0946 * * *$ & $-0.0785^{* * *}$ & $-0.0934 * * *$ & 0.00601 & 0.00747 & 0.00861 & $0.0120 * * *$ & 0.0119 & 0.00818 \\
\hline & $(0.0151)$ & $(0.0265)$ & $(0.0296)$ & $(0.00476)$ & (0.0113) & $(0.00728)$ & $(0.00433)$ & (0.00789) & $(0.00983)$ \\
\hline \multirow[t]{2}{*}{ Log(\# affiliates) } & -0.00202 & -0.00402 & -0.00195 & -0.000500 & 0.00158 & -0.00107 & 0.000892 & 0.00141 & 0.00142 \\
\hline & $(0.00290)$ & $(0.00482)$ & $(0.00673)$ & $(0.000834)$ & $(0.00187)$ & $(0.00131)$ & $(0.000945)$ & $(0.00151)$ & $(0.00170)$ \\
\hline \multirow[t]{2}{*}{ Share EU immigrants } & 0.0178 & -0.0275 & 0.00425 & 0.00293 & 0.00402 & -0.00919 & 0.00244 & 0.00797 & 0.000812 \\
\hline & $(0.0324)$ & $(0.0243)$ & (0.0795) & $(0.0135)$ & (0.0155) & $(0.0213)$ & $(0.00887)$ & $(0.0120)$ & $(0.0230)$ \\
\hline \multirow[t]{2}{*}{ Recession-proof } & $0.0356 * * *$ & $0.0195^{* *}$ & $0.0606 * * *$ & -0.00402 & -0.00188 & -0.00592 & $-0.00628 * *$ & $-0.00663^{*}$ & $-0.0113 * *$ \\
\hline & (0.00779) & $(0.00758)$ & $(0.0143)$ & $(0.00351)$ & $(0.00321)$ & $(0.00829)$ & (0.00259) & $(0.00334)$ & $(0.00489)$ \\
\hline \multirow[t]{2}{*}{ Exporter } & $0.0139 * *$ & 0.000739 & $0.0319 * *$ & $0.00578 * *$ & 0.00765 & 0.00186 & -0.000489 & 0.00122 & -0.00216 \\
\hline & $(0.00685)$ & $(0.0111)$ & $(0.0135)$ & $(0.00239)$ & $(0.00562)$ & (0.00439) & $(0.00215)$ & $(0.00353)$ & $(0.00429)$ \\
\hline \multirow[t]{2}{*}{ Importer } & -0.00160 & -0.00730 & 0.00561 & $0.00731^{* *}$ & 0.0116 & 0.00374 & 0.000656 & 0.00109 & -0.00400 \\
\hline & $(0.00796)$ & $(0.0141)$ & (0.0124) & $(0.00353)$ & $(0.00694)$ & $(0.00607)$ & $(0.00185)$ & $(0.00437)$ & $(0.00282)$ \\
\hline \multirow[t]{2}{*}{ Exp.-Importer } & $0.0224 * *$ & 0.0235 & 0.0112 & -0.00539 & -0.00702 & -0.00363 & -0.00388 & -0.00473 & 0.0104 \\
\hline & (0.00997) & (0.0148) & (0.0179) & $(0.00502)$ & $(0.00824)$ & $(0.00984)$ & (0.00485) & $(0.00558)$ & $(0.00794)$ \\
\hline \multirow[t]{2}{*}{ EU MFN_broad } & & -0.0267 & & & $-0.0446 * *$ & & & -0.0137 & \\
\hline & & (0.0393) & & & $(0.0208)$ & & & (0.0150) & \\
\hline \multirow[t]{2}{*}{ STRI_broad } & & & 0.0819 & & & 0.00173 & & & $-0.0247^{*}$ \\
\hline & & & $(0.0505)$ & & & $(0.0177)$ & & & $(0.0132)$ \\
\hline Observations & 352 & 131 & 130 & 353 & 131 & 130 & 353 & 131 & 130 \\
\hline R-squared & 0.372 & 0.398 & 0.339 & 0.075 & 0.131 & 0.098 & 0.071 & 0.143 & 0.099 \\
\hline
\end{tabular}


Table 6: Alternative Measures for Importance of UK and EU Affiliates (columns 1-3: sales shares; columns 4-6: segment sales)

\begin{tabular}{|c|c|c|c|c|c|c|}
\hline Date & 24-Jun-16 & 17-Oct-16 & 17-Jan-17 & 24-Jun-16 & 17-Oct-16 & 17-Jan-17 \\
\hline & (1) & (2) & (3) & (4) & (5) & (6) \\
\hline VARIABLES & $A R(t)$ & $A R(t)$ & $A R(t)$ & $A R(t)$ & $A R(t)$ & $A R(t)$ \\
\hline \multirow[t]{2}{*}{ ROA } & -0.0488 & -0.0201 & -0.0145 & $-0.122 * *$ & -0.0292 & -0.0276 \\
\hline & $(0.0356)$ & (0.0129) & $(0.0108)$ & $(0.0530)$ & $(0.0260)$ & $(0.0264)$ \\
\hline \multirow[t]{2}{*}{ Log(sales) } & $0.00453^{*}$ & 0.000679 & -0.000770 & 0.00109 & 0.000533 & 0.000602 \\
\hline & $(0.00254)$ & $(0.000848)$ & $(0.000702)$ & (0.00398) & $(0.00112)$ & $(0.00154)$ \\
\hline \multirow[t]{2}{*}{ Non-GBP currency } & $0.0332 * * *$ & $0.00762^{*}$ & 0.00366 & 0.0131 & 0.00750 & 0.00604 \\
\hline & $(0.00860)$ & $(0.00407)$ & $(0.00325)$ & $(0.00926)$ & $(0.00495)$ & $(0.00508)$ \\
\hline \multirow[t]{2}{*}{ Share EU affiliates } & $-0.0601 * *$ & -0.00455 & 0.00255 & -0.0446 & -0.00293 & 0.00981 \\
\hline & $(0.0252)$ & $(0.00797)$ & $(0.00707)$ & $(0.0273)$ & $(0.00810)$ & $(0.00941)$ \\
\hline \multirow[t]{2}{*}{ Share UK affiliates } & $-0.0919 * * *$ & 0.00620 & $0.0120 * *$ & $-0.111 * * *$ & -0.00311 & $0.0170 * * *$ \\
\hline & (0.0159) & $(0.00504)$ & $(0.00472)$ & (0.0177) & $(0.00510)$ & $(0.00495)$ \\
\hline \multirow[t]{2}{*}{ Log(\# affiliates) } & -0.00195 & -0.00131 & 0.000642 & -0.00500 & -0.00140 & 0.000818 \\
\hline & $(0.00403)$ & $(0.00103)$ & $(0.000900)$ & $(0.00336)$ & $(0.00123)$ & $(0.00150)$ \\
\hline \multirow[t]{2}{*}{ Share EU immigrants } & 0.0432 & -0.000228 & -0.00579 & -0.0165 & 0.00541 & 0.0192 \\
\hline & $(0.0356)$ & $(0.0171)$ & $(0.0106)$ & $(0.0490)$ & $(0.0180)$ & (0.0190) \\
\hline \multirow[t]{2}{*}{ Recession-proof } & $0.0303 * * *$ & -0.00396 & $-0.00449 *$ & $0.0509 * * *$ & -0.00355 & -0.00435 \\
\hline & $(0.00694)$ & $(0.00391)$ & $(0.00265)$ & $(0.00953)$ & $(0.00541)$ & $(0.00533)$ \\
\hline \multirow[t]{2}{*}{ Exporter } & $0.0140^{*}$ & $0.00495^{*}$ & 0.000461 & 0.00839 & $0.00867 * *$ & 0.00449 \\
\hline & $(0.00764)$ & $(0.00271)$ & $(0.00230)$ & $(0.00847)$ & $(0.00338)$ & $(0.00396)$ \\
\hline \multirow[t]{2}{*}{ Importer } & -0.00676 & $0.00866^{* *}$ & 0.00242 & -0.0108 & $0.00733^{*}$ & 0.00170 \\
\hline & $(0.00885)$ & $(0.00401)$ & $(0.00221)$ & $(0.0135)$ & $(0.00432)$ & $(0.00342)$ \\
\hline \multirow[t]{2}{*}{ Exp.-Importer } & $0.0236 * *$ & -0.00410 & -0.00496 & 0.0198 & $-0.0158 * *$ & -0.0183 \\
\hline & $(0.0116)$ & $(0.00599)$ & $(0.00531)$ & $(0.0174)$ & $(0.00706)$ & $(0.0112)$ \\
\hline Observations & 294 & 295 & 295 & 149 & 149 & 149 \\
\hline R-squared & 0.374 & 0.085 & 0.070 & 0.516 & 0.113 & 0.136 \\
\hline
\end{tabular}


Table 7: Augmented Abnormal Return Regressions (Four Market Indices: FTSE All Shares, S\&P 500, MSCI Asia, MSCl Europe)

\begin{tabular}{|c|c|c|c|c|c|c|c|c|c|}
\hline Date & 24 June 16 & 24 June 16 & 24 June 16 & 5 Oct 16 & 5 Oct 16 & 5 Oct 16 & 17 Jan 17 & 17 Jan 17 & 17 Jan 17 \\
\hline & (1) & $(2)$ & (3) & (4) & (5) & (6) & (7) & (8) & (9) \\
\hline VARIABLES & $A R(t)$ & $A R(t)$ & $A R(t)$ & $A R(t)$ & $A R(t)$ & $A R(t)$ & $A R(t)$ & $A R(t)$ & $A R(t)$ \\
\hline \multirow[t]{2}{*}{ ROA } & $-0.101 * * *$ & $-0.120 * * *$ & -0.0806 & -0.0225 & -0.0150 & $-0.0349 * *$ & 0.00166 & 0.0106 & 0.00539 \\
\hline & $(0.0374)$ & $(0.0321)$ & $(0.0908)$ & $(0.0139)$ & $(0.0187)$ & $(0.0156)$ & $(0.0123)$ & $(0.0176)$ & $(0.0205)$ \\
\hline \multirow[t]{2}{*}{ Log(sales) } & 0.00238 & $0.00855^{* *}$ & -0.00240 & 0.000912 & -0.000327 & $0.00278 * *$ & -0.000730 & -0.00226 & 0.000446 \\
\hline & $(0.00213)$ & $(0.00366)$ & $(0.00410)$ & $(0.000771)$ & $(0.00168)$ & $(0.00115)$ & $(0.000787)$ & $(0.00136)$ & $(0.00121)$ \\
\hline \multirow[t]{2}{*}{ Non-GBP currency } & $0.0413 * * *$ & $0.0349 * *$ & 0.0245 & 0.00487 & 0.00248 & 0.00522 & -0.000427 & 0.000936 & 0.00572 \\
\hline & $(0.00941)$ & $(0.0136)$ & $(0.0212)$ & $(0.00370)$ & $(0.00592)$ & $(0.00455)$ & $(0.00308)$ & $(0.00587)$ & $(0.00493)$ \\
\hline \multirow[t]{2}{*}{ Share EU affiliates } & $-0.0495^{*}$ & $-0.0816^{* *}$ & -0.0500 & 0.000934 & 0.00256 & -0.000559 & 0.00660 & -0.000214 & 0.0153 \\
\hline & $(0.0277)$ & $(0.0324)$ & $(0.0772)$ & $(0.00688)$ & $(0.0157)$ & $(0.0112)$ & $(0.00664)$ & $(0.0132)$ & (0.0108) \\
\hline \multirow[t]{2}{*}{ Share UK affiliates } & $-0.0956 * * *$ & $-0.0862 * * *$ & $-0.102 * * *$ & 0.00632 & 0.00879 & 0.00965 & $0.0126 * * *$ & 0.0149 & 0.0113 \\
\hline & (0.0169) & $(0.0284)$ & $(0.0300)$ & $(0.00481)$ & $(0.0117)$ & $(0.00700)$ & $(0.00443)$ & $(0.00920)$ & $(0.00894)$ \\
\hline \multirow[t]{2}{*}{ Log(\# affiliates) } & -0.00242 & -0.00446 & -0.00165 & -0.000480 & 0.00159 & -0.00111 & 0.00106 & 0.00158 & 0.00127 \\
\hline & $(0.00278)$ & $(0.00485)$ & $(0.00624)$ & $(0.000843)$ & $(0.00187)$ & $(0.00124)$ & $(0.000938)$ & (0.00159) & $(0.00150)$ \\
\hline \multirow[t]{2}{*}{ Share EU immigrants } & -0.00207 & -0.0357 & -0.0167 & 0.00524 & 0.00421 & -0.00756 & 0.0102 & 0.0118 & 0.00973 \\
\hline & $(0.0363)$ & $(0.0319)$ & $(0.0849)$ & $(0.0137)$ & $(0.0154)$ & $(0.0209)$ & $(0.0102)$ & $(0.0149)$ & $(0.0237)$ \\
\hline \multirow[t]{2}{*}{ Recession-proof } & $0.0231 * *$ & 0.00119 & $0.0547 * * *$ & -0.00270 & 0.000130 & -0.00522 & -0.00151 & 0.000247 & $-0.00895 * *$ \\
\hline & $(0.00907)$ & $(0.0105)$ & $(0.0138)$ & (0.00359) & $(0.00323)$ & $(0.00809)$ & $(0.00292)$ & $(0.00426)$ & $(0.00441)$ \\
\hline \multirow[t]{2}{*}{ Exporter } & $0.0125^{*}$ & -0.00106 & $0.0272^{*}$ & $0.00630 * * *$ & 0.00808 & 0.00283 & -0.000112 & 0.00176 & -0.000535 \\
\hline & $(0.00694)$ & $(0.0111)$ & $(0.0137)$ & $(0.00238)$ & $(0.00564)$ & $(0.00441)$ & $(0.00225)$ & (0.00404) & $(0.00427)$ \\
\hline \multirow[t]{2}{*}{ Importer } & -0.000273 & -0.00265 & 0.00415 & $0.00706 * *$ & 0.0109 & 0.00399 & 0.000173 & -0.000647 & -0.00341 \\
\hline & $(0.00875)$ & $(0.0144)$ & $(0.0125)$ & $(0.00347)$ & $(0.00673)$ & $(0.00594)$ & $(0.00220)$ & $(0.00520)$ & $(0.00287)$ \\
\hline \multirow[t]{2}{*}{ Exp.-Importer } & $0.0255^{* *}$ & 0.0238 & 0.0203 & -0.00596 & -0.00716 & -0.00521 & -0.00470 & -0.00494 & 0.00702 \\
\hline & $(0.0111)$ & $(0.0160)$ & $(0.0187)$ & $(0.00496)$ & $(0.00815)$ & $(0.00967)$ & $(0.00506)$ & $(0.00643)$ & $(0.00780)$ \\
\hline \multirow[t]{2}{*}{ EU MFN_broad } & & -0.000967 & & & $-0.0482 * *$ & & & -0.0233 & \\
\hline & & $(0.0447)$ & & & $(0.0212)$ & & & $(0.0180)$ & \\
\hline \multirow[t]{2}{*}{ STRI_broad } & & & 0.0628 & & & 0.00401 & & & -0.0182 \\
\hline & & & $(0.0501)$ & & & $(0.0171)$ & & & $(0.0127)$ \\
\hline Observations & 352 & 131 & 130 & 353 & 131 & 130 & 353 & 131 & 130 \\
\hline R-squared & 0.376 & 0.437 & 0.334 & 0.059 & 0.111 & 0.100 & 0.057 & 0.122 & 0.076 \\
\hline
\end{tabular}


Table 8: Allowing for Event-Induced Changes in Market Model Parameters

\begin{tabular}{|c|c|c|c|c|c|c|c|c|c|}
\hline Date & 24 June 16 & 24 June 16 & 24 June 16 & 5 Oct 16 & 5 Oct 16 & 5 Oct 16 & 17 Jan 17 & 17 Jan 17 & 17 Jan 17 \\
\hline & (1) & (2) & (3) & (4) & (5) & (6) & (7) & (8) & (9) \\
\hline VARIABLES & $A R(t)$ & $A R(t)$ & $A R(t)$ & $A R(t)$ & $A R(t)$ & $A R(t)$ & $A R(t)$ & $A R(t)$ & $A R(t)$ \\
\hline \multirow[t]{2}{*}{ ROA } & $-0.0494 * *$ & -0.0406 & -0.0638 & $-0.0187^{* *}$ & $-0.0204 * * *$ & -0.0234 & -0.00142 & -0.00270 & 0.0114 \\
\hline & $(0.0226)$ & $(0.0362)$ & $(0.0474)$ & $(0.00775)$ & $(0.00632)$ & $(0.0158)$ & (0.00559) & $(0.00805)$ & $(0.00761)$ \\
\hline \multirow[t]{2}{*}{ Log(sales) } & $-4.39 e-05$ & 0.00321 & -0.00209 & 0.000398 & -0.00104 & $0.00155^{*}$ & $-9.91 e-06$ & -0.000700 & -0.000140 \\
\hline & $(0.00137)$ & $(0.00244)$ & $(0.00253)$ & $(0.000536)$ & $(0.000922)$ & (0.000849) & $(0.000297)$ & $(0.000502)$ & $(0.000554)$ \\
\hline \multirow[t]{2}{*}{ Non-GBP currency } & $0.0135 * *$ & 0.00565 & 0.0124 & $0.00373 *$ & 0.00217 & 0.00498 & 0.00153 & $0.00461 * *$ & 0.00196 \\
\hline & $(0.00546)$ & $(0.00786)$ & $(0.0142)$ & $(0.00203)$ & $(0.00338)$ & $(0.00352)$ & $(0.00126)$ & $(0.00187)$ & $(0.00192)$ \\
\hline \multirow[t]{2}{*}{ Share EU affiliates } & $-0.0289 *$ & $-0.0442 * *$ & -0.0292 & 0.00229 & -0.00168 & 0.00723 & 0.00453 & -0.00109 & 0.00143 \\
\hline & $(0.0169)$ & $(0.0218)$ & $(0.0515)$ & $(0.00476)$ & $(0.00927)$ & $(0.00714)$ & (0.00319) & $(0.00626)$ & $(0.00361)$ \\
\hline \multirow[t]{2}{*}{ Share UK affiliates } & $-0.0648 * * *$ & $-0.0513^{* * *}$ & $-0.0689 * * *$ & $0.00675^{* *}$ & 0.00501 & 0.00734 & 0.00227 & -0.00610 & 0.00242 \\
\hline & $(0.00936)$ & $(0.0167)$ & $(0.0195)$ & $(0.00307)$ & $(0.00663)$ & $(0.00492)$ & $(0.00217)$ & $(0.00505)$ & $(0.00266)$ \\
\hline \multirow[t]{2}{*}{ Log(\# affiliates) } & -0.00201 & -0.00268 & -0.00280 & $-4.36 e-05$ & 0.00160 & -0.000888 & 0.000313 & -0.000588 & 0.000822 \\
\hline & $(0.00171)$ & $(0.00315)$ & $(0.00370)$ & $(0.000629)$ & $(0.00124)$ & $(0.00112)$ & $(0.000461)$ & $(0.000739)$ & $(0.000908)$ \\
\hline \multirow[t]{2}{*}{ Share EU immigrants } & 0.0210 & -0.0114 & 0.0280 & -0.00494 & -0.0106 & -0.00669 & $-9.55 e-05$ & -0.00242 & 0.0124 \\
\hline & $(0.0201)$ & $(0.0190)$ & $(0.0515)$ & $(0.00873)$ & $(0.00906)$ & $(0.0144)$ & (0.00469) & $(0.00451)$ & $(0.00889)$ \\
\hline \multirow[t]{2}{*}{ Recession-proof } & $0.0235^{* * *}$ & $0.0183^{* * *}$ & $0.0384 * * *$ & -0.00237 & 0.000740 & $-6.13 e-05$ & -0.000943 & -0.000354 & -0.00150 \\
\hline & $(0.00447)$ & $(0.00504)$ & $(0.00954)$ & $(0.00244)$ & $(0.00293)$ & $(0.00527)$ & $(0.00111)$ & $(0.00126)$ & $(0.00157)$ \\
\hline \multirow[t]{2}{*}{ Exporter } & 0.00363 & -0.00610 & 0.0145 & $0.00275^{*}$ & 0.00259 & -0.000174 & -0.00169 & -0.00278 & -0.00264 \\
\hline & (0.00459) & $(0.00784)$ & $(0.00896)$ & $(0.00155)$ & $(0.00296)$ & $(0.00314)$ & $(0.00121)$ & (0.00169) & $(0.00205)$ \\
\hline \multirow[t]{2}{*}{ Importer } & -0.00280 & -0.0120 & 0.00336 & 0.00294 & 0.00497 & 0.00331 & 0.000139 & -0.00118 & -0.00209 \\
\hline & $(0.00518)$ & $(0.00931)$ & $(0.00745)$ & $(0.00230)$ & $(0.00388)$ & (0.00419) & $(0.00136)$ & $(0.00323)$ & $(0.00184)$ \\
\hline \multirow[t]{2}{*}{ Exp.-Importer } & $0.0161 * *$ & $0.0242 * *$ & 0.0115 & -0.00190 & -0.00116 & -0.00208 & 0.000321 & 0.00205 & 0.00327 \\
\hline & $(0.00708)$ & $(0.0103)$ & $(0.0126)$ & $(0.00341)$ & $(0.00518)$ & $(0.00641)$ & $(0.00200)$ & $(0.00374)$ & $(0.00335)$ \\
\hline \multirow[t]{2}{*}{ EU MFN_broad } & & -0.0216 & & & $-0.0228 *$ & & & 0.000638 & \\
\hline & & $(0.0268)$ & & & $(0.0124)$ & & & $(0.00706)$ & \\
\hline \multirow[t]{2}{*}{ STRI_broad } & & & $0.0545^{*}$ & & & -0.00487 & & & -0.00287 \\
\hline & & & $(0.0300)$ & & & $(0.0104)$ & & & $(0.00595)$ \\
\hline Observations & 352 & 131 & 130 & 353 & 131 & 130 & 353 & 131 & 130 \\
\hline R-squared & 0.319 & 0.293 & 0.327 & 0.058 & 0.134 & 0.108 & 0.023 & 0.106 & 0.058 \\
\hline
\end{tabular}


Table 9: Overall Returns as Dependent Variable

\begin{tabular}{|c|c|c|c|c|c|c|c|c|c|}
\hline Date & 24 June 16 & 24 June 16 & 24 June 16 & 5 Oct 16 & 5 Oct 16 & 5 Oct 16 & 17 Jan 17 & 17 Jan 17 & 17 Jan 17 \\
\hline & (1) & $(2)$ & (3) & (4) & (5) & (6) & (7) & (8) & (9) \\
\hline VARIABLES & $A R(t)$ & $\mathrm{AR}(\mathrm{t})$ & $A R(t)$ & $\mathrm{AR}(\mathrm{t})$ & $A R(t)$ & $A R(t)$ & $A R(t)$ & $A R(t)$ & $A R(t)$ \\
\hline \multirow[t]{2}{*}{ ROA } & -0.0228 & 0.00428 & -0.00957 & $-0.0214^{*}$ & -0.0124 & $-0.0315^{* *}$ & -0.00105 & 0.00840 & 0.0106 \\
\hline & $(0.0338)$ & $(0.0403)$ & $(0.0803)$ & $(0.0128)$ & $(0.0161)$ & $(0.0153)$ & $(0.00953)$ & $(0.0134)$ & $(0.0180)$ \\
\hline \multirow[t]{2}{*}{ Log(sales) } & -0.00259 & 0.00166 & -0.00453 & 0.000336 & -0.00119 & $0.00198^{*}$ & $-0.00186 * *$ & $-0.00407 * * *$ & -0.00140 \\
\hline & $(0.00229)$ & $(0.00403)$ & $(0.00430)$ & $(0.000738)$ & $(0.00152)$ & $(0.00114)$ & $(0.000777)$ & $(0.00133)$ & $(0.00126)$ \\
\hline \multirow[t]{2}{*}{ Non-GBP currency } & $0.0251 * * *$ & 0.0189 & 0.0211 & 0.00437 & 0.00325 & 0.00368 & -0.00231 & 0.00220 & 0.000432 \\
\hline & $(0.00828)$ & $(0.0131)$ & $(0.0217)$ & $(0.00334)$ & $(0.00524)$ & $(0.00424)$ & $(0.00256)$ & $(0.00515)$ & $(0.00467)$ \\
\hline \multirow[t]{2}{*}{ Share EU affiliates } & -0.0338 & $-0.0694 * *$ & -0.0396 & 0.00122 & 0.00228 & -0.00123 & 0.00700 & -0.00215 & 0.0162 \\
\hline & $(0.0274)$ & $(0.0297)$ & $(0.0800)$ & $(0.00653)$ & $(0.0142)$ & $(0.0108)$ & $(0.00608)$ & $(0.0106)$ & $(0.0119)$ \\
\hline \multirow[t]{2}{*}{ Share UK affiliates } & $-0.0915^{* * *}$ & $-0.0716^{* *}$ & $-0.0922 * * *$ & 0.00616 & 0.00838 & 0.00855 & $0.0128 * * *$ & $0.0140^{*}$ & 0.00840 \\
\hline & $(0.0147)$ & $(0.0277)$ & $(0.0297)$ & $(0.00469)$ & $(0.0108)$ & $(0.00677)$ & $(0.00412)$ & $(0.00714)$ & $(0.00866)$ \\
\hline \multirow[t]{2}{*}{ Log(\# affiliates) } & -0.00284 & -0.00292 & -0.00269 & -0.000652 & 0.00174 & -0.00123 & 0.000605 & 0.00176 & 0.00115 \\
\hline & $(0.00289)$ & (0.00529) & $(0.00678)$ & $(0.000831)$ & $(0.00175)$ & $(0.00126)$ & $(0.000947)$ & $(0.00147)$ & $(0.00163)$ \\
\hline \multirow[t]{2}{*}{ Share EU immigrants } & 0.0252 & -0.0255 & 0.00930 & 0.00476 & 0.00476 & -0.00695 & 0.00538 & 0.00897 & 0.00362 \\
\hline & $(0.0333)$ & $(0.0264)$ & $(0.0812)$ & $(0.0130)$ & $(0.0142)$ & $(0.0218)$ & $(0.00826)$ & $(0.0120)$ & $(0.0215)$ \\
\hline \multirow[t]{2}{*}{ Recession-proof } & $0.0437^{* * *}$ & $0.0261 * * *$ & $0.0701 * * *$ & -0.00267 & -0.000925 & -0.00443 & -0.00359 & -0.00453 & $-0.00817^{*}$ \\
\hline & $(0.00823)$ & $(0.00797)$ & $(0.0152)$ & $(0.00344)$ & $(0.00295)$ & $(0.00814)$ & $(0.00246)$ & $(0.00333)$ & $(0.00472)$ \\
\hline \multirow[t]{2}{*}{ Exporter } & $0.0139 *$ & -0.00189 & $0.0371 * * *$ & $0.00564 * *$ & 0.00701 & 0.00251 & -0.000595 & 0.000173 & -0.000591 \\
\hline & $(0.00727)$ & $(0.0133)$ & $(0.0133)$ & $(0.00228)$ & $(0.00501)$ & $(0.00431)$ & $(0.00210)$ & $(0.00360)$ & $(0.00416)$ \\
\hline \multirow[t]{2}{*}{ Importer } & -0.00512 & -0.0180 & 0.00914 & $0.00675^{*}$ & 0.00976 & 0.00444 & -0.000504 & -0.00252 & -0.00273 \\
\hline & $(0.00806)$ & $(0.0167)$ & $(0.0125)$ & $(0.00344)$ & $(0.00639)$ & $(0.00609)$ & $(0.00190)$ & $(0.00506)$ & $(0.00258)$ \\
\hline \multirow[t]{2}{*}{ Exp.-Importer } & $0.0250 * *$ & $0.0306^{*}$ & 0.00675 & -0.00506 & -0.00598 & -0.00446 & -0.00305 & -0.00246 & 0.00880 \\
\hline & $(0.0102)$ & (0.0169) & $(0.0191)$ & $(0.00482)$ & $(0.00762)$ & $(0.00986)$ & $(0.00473)$ & $(0.00607)$ & $(0.00751)$ \\
\hline \multirow[t]{2}{*}{ EU MFN_broad } & & 0.00852 & & & $-0.0377^{*}$ & & & -0.00113 & \\
\hline & & $(0.0453)$ & & & $(0.0195)$ & & & $(0.0150)$ & \\
\hline \multirow[t]{2}{*}{ STRI_broad } & & & $0.108 * *$ & & & 0.00611 & & & -0.0158 \\
\hline & & & $(0.0518)$ & & & $(0.0174)$ & & & $(0.0122)$ \\
\hline Observations & 352 & 131 & 130 & 353 & 131 & 130 & 353 & 131 & 130 \\
\hline R-squared & 0.313 & 0.260 & 0.321 & 0.054 & 0.109 & 0.072 & 0.117 & 0.228 & 0.098 \\
\hline
\end{tabular}


Table 10: Longer Event Windows ( $t-1$ to $t+1)$

\begin{tabular}{|c|c|c|c|c|c|c|c|c|c|}
\hline \multirow[t]{2}{*}{ Date } & $\begin{array}{c}23,24,27 \\
\text { June } 16\end{array}$ & $\begin{array}{c}23,24,27 \\
\text { June } 16\end{array}$ & $\begin{array}{c}23,24,27 \\
\text { June } 16\end{array}$ & 4-6 Oct 16 & 4-6 Oct 16 & 4-6 Oct 16 & 16-18 Jan 17 & 16-18 Jan 17 & 16-18 Jan 17 \\
\hline & (1) & (2) & (3) & (4) & (5) & (6) & (7) & (8) & (9) \\
\hline VARIABLES & $A R(t-1, t+1)$ & $A R(t-1, t+1)$ & $A R(t-1, t+1)$ & $A R(t-1, t+1)$ & $A R(t-1, t+1)$ & $\operatorname{AR}(t-1, t+1)$ & $A R(t-1, t+1)$ & $A R(t-1, t+1)$ & $\operatorname{AR}(t-1, t+1)$ \\
\hline \multirow[t]{2}{*}{ ROA } & -0.0629 & -0.0813 & 0.0133 & -0.0159 & 0.0289 & $-0.0539 *$ & -0.0206 & -0.0186 & -0.00173 \\
\hline & $(0.0501)$ & $(0.0764)$ & $(0.0914)$ & $(0.0262)$ & $(0.0380)$ & $(0.0299)$ & $(0.0154)$ & $(0.0236)$ & $(0.0346)$ \\
\hline \multirow[t]{2}{*}{ Log(sales) } & 0.00214 & $0.0156 * *$ & -0.00115 & $0.00234 *$ & $0.00505^{*}$ & $0.00372^{* *}$ & -0.000232 & -0.00259 & $-8.39 e-05$ \\
\hline & $(0.00384)$ & (0.00779) & $(0.00743)$ & $(0.00140)$ & $(0.00290)$ & $(0.00182)$ & $(0.00102)$ & $(0.00222)$ & $(0.00150)$ \\
\hline \multirow[t]{2}{*}{ Non-GBP currency } & $0.0760 * * *$ & $0.0525 * *$ & $0.0668 * *$ & -0.00804 & $-0.0264 * *$ & 0.00510 & 0.00313 & $0.0155^{*}$ & -0.00233 \\
\hline & $(0.0141)$ & $(0.0231)$ & $(0.0293)$ & (0.00599) & $(0.0109)$ & $(0.00786)$ & $(0.00463)$ & $(0.00850)$ & $(0.00925)$ \\
\hline \multirow[t]{2}{*}{ Share EU affiliates } & $-0.0683 * *$ & $-0.107^{* *}$ & -0.0845 & 0.00910 & 0.0359 & -0.0172 & 0.00640 & 0.00257 & 0.000683 \\
\hline & $(0.0338)$ & $(0.0496)$ & $(0.0797)$ & $(0.0157)$ & $(0.0329)$ & $(0.0174)$ & $(0.00975)$ & $(0.0182)$ & (0.0159) \\
\hline \multirow[t]{2}{*}{ Share UK affiliates } & $-0.150 * * *$ & $-0.129 * * *$ & $-0.126 * * *$ & -0.00393 & -0.00559 & -0.00351 & 0.00108 & -0.0129 & -0.00369 \\
\hline & $(0.0221)$ & $(0.0418)$ & $(0.0409)$ & $(0.00958)$ & $(0.0191)$ & $(0.0131)$ & $(0.00767)$ & $(0.0168)$ & $(0.0126)$ \\
\hline \multirow[t]{2}{*}{ Log(\# affiliates) } & 0.00251 & -0.00658 & 0.00680 & 0.00164 & -0.00152 & -0.000381 & -0.000553 & -0.000715 & 0.000455 \\
\hline & (0.00529) & $(0.00934)$ & $(0.00948)$ & $(0.00167)$ & $(0.00365)$ & $(0.00201)$ & $(0.00126)$ & $(0.00290)$ & $(0.00200)$ \\
\hline \multicolumn{10}{|l|}{ Share EU } \\
\hline \multirow[t]{2}{*}{ immigrants } & 0.0155 & -0.0524 & -0.0664 & $0.0452 * *$ & $0.0517^{*}$ & 0.0358 & -0.00375 & -0.0139 & $0.0597^{*}$ \\
\hline & $(0.0462)$ & $(0.0525)$ & $(0.134)$ & $(0.0224)$ & $(0.0302)$ & $(0.0415)$ & $(0.0214)$ & $(0.0270)$ & $(0.0323)$ \\
\hline \multirow[t]{2}{*}{ Recession-proof } & $0.0671 * * *$ & 0.0260 & $0.101^{* * *}$ & -0.00371 & -0.00327 & -0.0123 & -0.00447 & $-0.0104^{*}$ & -0.00749 \\
\hline & $(0.0110)$ & $(0.0161)$ & $(0.0250)$ & $(0.00710)$ & $(0.00713)$ & $(0.0112)$ & $(0.00442)$ & $(0.00619)$ & $(0.00697)$ \\
\hline \multirow[t]{2}{*}{ Exporter } & $0.0234^{*}$ & 0.00240 & $0.0494 * *$ & 0.00175 & $0.0154^{*}$ & -0.00951 & -0.00152 & -0.00648 & 0.00145 \\
\hline & $(0.0120)$ & $(0.0214)$ & $(0.0238)$ & $(0.00471)$ & $(0.00905)$ & $(0.00762)$ & $(0.00448)$ & $(0.00720)$ & $(0.00557)$ \\
\hline \multirow[t]{2}{*}{ Importer } & -0.00154 & -0.00787 & 0.0163 & 0.00270 & 0.00389 & 0.000199 & $0.00981 * *$ & 0.0164 & 0.00180 \\
\hline & $(0.0141)$ & $(0.0265)$ & $(0.0260)$ & $(0.00496)$ & $(0.00838)$ & $(0.00821)$ & $(0.00465)$ & $(0.0105)$ & $(0.00554)$ \\
\hline \multirow[t]{2}{*}{ Exp.-Importer } & $0.0391 * *$ & 0.0342 & 0.0116 & 0.00508 & -0.00939 & 0.00963 & -0.00664 & -0.0149 & 0.00452 \\
\hline & $(0.0187)$ & $(0.0320)$ & $(0.0375)$ & $(0.00840)$ & $(0.0123)$ & $(0.0132)$ & $(0.00730)$ & $(0.0144)$ & (0.00998) \\
\hline \multirow[t]{2}{*}{ EU MFN_broad } & & -0.0213 & & & $-0.0697^{*}$ & & & 0.0132 & \\
\hline & & $(0.0705)$ & & & $(0.0416)$ & & & $(0.0264)$ & \\
\hline \multirow[t]{2}{*}{ STRI_broad } & & & 0.110 & & & -0.0171 & & & 0.00660 \\
\hline & & & $(0.0755)$ & & & $(0.0223)$ & & & $(0.0169)$ \\
\hline Observations & 353 & 131 & 130 & 353 & 131 & 130 & 353 & 131 & 130 \\
\hline R-squared & 0.388 & 0.395 & 0.329 & 0.053 & 0.181 & 0.105 & 0.028 & 0.106 & 0.054 \\
\hline
\end{tabular}


Table 11: Longer Event Windows (Event-Specific)

\begin{tabular}{|c|c|c|c|c|c|c|c|c|c|}
\hline Date & $23 / 6-1 / 7 / 16$ & $23 / 6-1 / 7 / 16$ & $23 / 6-1 / 7 / 16$ & 3-7 Oct 16 & 3-7 Oct 16 & 3-7 Oct 16 & 16-20 Jan 17 & 16-20 Jan 17 & 16-20 Jan 17 \\
\hline & (1) & (2) & (3) & (4) & (5) & (6) & (7) & (8) & (9) \\
\hline VARIABLES & $A R(t-1, t+5)$ & $\mathrm{AR}(\mathrm{t}-1, \mathrm{t}+5)$ & $A R(t-1, t+5)$ & $A R(t-2, t+2)$ & $A R(t-2, t+2)$ & $A R(t-2, t+2)$ & $A R(t-1, t+3)$ & $A R(t-1, t+3)$ & $A R(t-1, t+3)$ \\
\hline \multirow[t]{2}{*}{ ROA } & -0.0846 & $-0.190 * * *$ & 0.0493 & -0.0504 & 0.000228 & $-0.100 * *$ & $-0.0445^{*}$ & -0.0276 & -0.0794 \\
\hline & $(0.0669)$ & $(0.0650)$ & $(0.133)$ & $(0.0353)$ & $(0.0407)$ & $(0.0385)$ & $(0.0238)$ & $(0.0304)$ & $(0.0616)$ \\
\hline \multirow[t]{2}{*}{ Log(sales) } & -0.00661 & 0.00299 & -0.0117 & -0.00154 & 0.00424 & -0.00297 & -0.000661 & -0.00366 & 0.00103 \\
\hline & $(0.00451)$ & (0.00798) & $(0.00915)$ & (0.00176) & $(0.00256)$ & $(0.00244)$ & $(0.00124)$ & $(0.00281)$ & $(0.00224)$ \\
\hline \multirow[t]{2}{*}{ Non-GBP currency } & $0.0642 * * *$ & 0.0383 & $0.0674 * *$ & 0.00738 & -0.00888 & 0.0120 & 0.000883 & 0.0126 & -0.0110 \\
\hline & $(0.0154)$ & $(0.0230)$ & $(0.0296)$ & $(0.00780)$ & $(0.0113)$ & (0.0119) & $(0.00626)$ & $(0.0106)$ & $(0.0148)$ \\
\hline \multirow[t]{2}{*}{ Share EU affiliates } & -0.0674 & -0.103 & -0.0811 & 0.00257 & 0.0574 & $-0.0585^{* *}$ & 0.00208 & 0.00549 & -0.00515 \\
\hline & $(0.0412)$ & $(0.0671)$ & $(0.0748)$ & (0.0194) & $(0.0354)$ & $(0.0222)$ & $(0.0120)$ & $(0.0251)$ & $(0.0190)$ \\
\hline \multirow[t]{2}{*}{ Share UK affiliates } & $-0.164 * * *$ & $-0.156 * * *$ & $-0.127 * * *$ & $-0.0341 * * *$ & -0.0255 & $-0.0430 * * *$ & -0.00129 & -0.000211 & -0.0139 \\
\hline & $(0.0243)$ & $(0.0526)$ & $(0.0416)$ & $(0.0118)$ & $(0.0213)$ & $(0.0158)$ & $(0.00862)$ & $(0.0216)$ & (0.0172) \\
\hline \multirow[t]{2}{*}{ Log(\# affiliates) } & 0.00310 & -0.00773 & 0.00889 & 0.000963 & -0.00164 & -0.000663 & -0.00182 & 0.00240 & -0.00347 \\
\hline & (0.00485) & (0.00997) & $(0.0116)$ & $(0.00218)$ & $(0.00333)$ & $(0.00229)$ & $(0.00183)$ & $(0.00378)$ & $(0.00347)$ \\
\hline \multirow[t]{2}{*}{ Share EU immigrants } & 0.0203 & -0.0185 & -0.0789 & 0.0375 & 0.0235 & 0.0358 & -0.0100 & -0.0291 & 0.0429 \\
\hline & $(0.0578)$ & $(0.0672)$ & $(0.136)$ & $(0.0287)$ & $(0.0354)$ & $(0.0534)$ & (0.0299) & $(0.0300)$ & $(0.0371)$ \\
\hline \multirow[t]{2}{*}{ Recession-proof } & $0.0951 * * *$ & $0.0483 * * *$ & $0.135^{* * *}$ & -0.00369 & $-0.0142^{*}$ & -0.00523 & -0.00797 & $-0.0203 * * *$ & -0.0121 \\
\hline & $(0.0155)$ & $(0.0143)$ & $(0.0308)$ & (0.00793) & $(0.00791)$ & $(0.0156)$ & $(0.00574)$ & $(0.00577)$ & (0.00793) \\
\hline \multirow[t]{2}{*}{ Exporter } & 0.0120 & -0.0245 & 0.0365 & 0.00543 & $0.0208^{*}$ & -0.0142 & 0.00317 & 0.000537 & 0.00941 \\
\hline & $(0.0130)$ & $(0.0241)$ & $(0.0246)$ & $(0.00569)$ & (0.0107) & $(0.00868)$ & $(0.00548)$ & $(0.00963)$ & $(0.00756)$ \\
\hline \multirow[t]{2}{*}{ Importer } & -0.00884 & -0.0448 & 0.0371 & 0.00760 & 0.0100 & 0.00579 & $0.0134^{*}$ & $0.0273 *$ & 0.00672 \\
\hline & (0.0167) & $(0.0373)$ & $(0.0233)$ & (0.00583) & $(0.0125)$ & (0.0108) & (0.00696) & (0.0158) & (0.00742) \\
\hline \multirow[t]{2}{*}{ Exp.-Importer } & 0.0339 & $0.0699 *$ & -0.0233 & 0.00499 & -0.00595 & 0.0123 & -0.0113 & $-0.0314^{*}$ & 0.000432 \\
\hline & $(0.0222)$ & $(0.0374)$ & $(0.0381)$ & (0.0107) & $(0.0170)$ & $(0.0193)$ & (0.00972) & (0.0187) & (0.0147) \\
\hline \multirow[t]{2}{*}{ EU MFN_broad } & & 0.00463 & & & -0.0300 & & & 0.0430 & \\
\hline & & $(0.0810)$ & & & $(0.0456)$ & & & $(0.0405)$ & \\
\hline \multirow[t]{2}{*}{ STRI_broad } & & & $0.184^{*}$ & & & -0.0303 & & & -0.000514 \\
\hline & & & $(0.102)$ & & & $(0.0233)$ & & & $(0.0186)$ \\
\hline Observations & 353 & 131 & 130 & 353 & 131 & 130 & 353 & 131 & 130 \\
\hline R-squared & 0.388 & 0.395 & 0.329 & 0.053 & 0.181 & 0.105 & 0.028 & 0.106 & 0.054 \\
\hline
\end{tabular}


Table 12: Longer Event Windows for the Referendum Event (20 and 60 days)

\begin{tabular}{|c|c|c|c|c|c|c|}
\hline Date & $23 / 6-20 / 7 / 16$ & $23 / 6-20 / 7 / 16$ & $23 / 6-20 / 7 / 16$ & $23 / 6-14 / 9 / 16$ & $23 / 6-14 / 9 / 16$ & 23/6-14/9/16 \\
\hline & (1) & $(2)$ & (3) & (4) & (5) & (6) \\
\hline VARIABLES & $A R(t-1, t+20)$ & $A R(t-1, t+20)$ & $A R(t-1, t+20)$ & $A R(t-1, t+60)$ & $A R(t-1, t+60)$ & $A R(t-1, t+60)$ \\
\hline \multirow[t]{2}{*}{ ROA } & -0.00314 & $-0.183^{* *}$ & 0.0675 & -0.117 & $-0.303 * * *$ & -0.00538 \\
\hline & $(0.0981)$ & $(0.0709)$ & (0.139) & $(0.128)$ & $(0.0829)$ & $(0.170)$ \\
\hline \multirow[t]{2}{*}{ Log(sales) } & -0.00660 & -0.00444 & -0.0101 & $-0.0147 * *$ & $-0.0203 * *$ & $-0.0160 *$ \\
\hline & (0.00489) & $(0.00954)$ & $(0.00787)$ & $(0.00585)$ & $(0.00958)$ & $(0.00884)$ \\
\hline \multirow[t]{2}{*}{ Non-GBP currency } & 0.0207 & 0.0221 & 0.00310 & 0.0288 & 0.0507 & -0.00710 \\
\hline & $(0.0192)$ & $(0.0248)$ & $(0.0344)$ & $(0.0263)$ & $(0.0426)$ & $(0.0423)$ \\
\hline \multirow[t]{2}{*}{ Share EU affiliates } & -0.0754 & -0.123 & -0.0912 & 0.0184 & 0.0167 & -0.0809 \\
\hline & $(0.0547)$ & $(0.0912)$ & $(0.107)$ & $(0.0690)$ & $(0.142)$ & $(0.110)$ \\
\hline \multirow[t]{2}{*}{ Share UK affiliates } & $-0.211 * * *$ & $-0.230 * * *$ & $-0.211 * * *$ & $-0.0917 * *$ & -0.129 & $-0.131 * *$ \\
\hline & $(0.0281)$ & $(0.0604)$ & $(0.0421)$ & $(0.0369)$ & $(0.0839)$ & $(0.0633)$ \\
\hline \multirow[t]{2}{*}{ Log(\# affiliates) } & -0.00260 & -0.00699 & 0.00214 & -0.000674 & 0.00137 & 0.000561 \\
\hline & $(0.00590)$ & $(0.0128)$ & $(0.0124)$ & $(0.00690)$ & $(0.0142)$ & $(0.0116)$ \\
\hline \multirow[t]{2}{*}{ Share EU immigrants } & 0.0368 & -0.00405 & -0.0157 & 0.0197 & -0.0454 & -0.0847 \\
\hline & $(0.0579)$ & $(0.0610)$ & $(0.127)$ & $(0.0729)$ & $(0.0718)$ & $(0.138)$ \\
\hline \multirow[t]{2}{*}{ Recession-proof } & $0.0676 * * *$ & 0.0305 & $0.0937 * * *$ & 0.0267 & -0.00694 & 0.0526 \\
\hline & (0.0159) & $(0.0193)$ & $(0.0291)$ & $(0.0180)$ & $(0.0245)$ & $(0.0447)$ \\
\hline \multirow[t]{2}{*}{ Exporter } & -0.000232 & -0.0405 & 0.00596 & 0.0236 & -0.00369 & 0.0345 \\
\hline & $(0.0165)$ & (0.0309) & $(0.0253)$ & (0.0197) & $(0.0297)$ & $(0.0316)$ \\
\hline \multirow[t]{2}{*}{ Importer } & -0.00918 & -0.0307 & -0.00275 & 0.00976 & 0.00288 & 0.0196 \\
\hline & $(0.0159)$ & $(0.0344)$ & (0.0198) & $(0.0210)$ & (0.0459) & $(0.0231)$ \\
\hline \multirow[t]{2}{*}{ Exp.-Importer } & $0.0464 *$ & 0.0625 & 0.0515 & 0.0205 & 0.00966 & 0.0413 \\
\hline & $(0.0269)$ & $(0.0461)$ & $(0.0337)$ & $(0.0364)$ & $(0.0617)$ & $(0.0626)$ \\
\hline \multirow[t]{2}{*}{ EU MFN_broad } & & 0.0341 & & & 0.0696 & \\
\hline & & $(0.0786)$ & & & $(0.0963)$ & \\
\hline \multirow[t]{2}{*}{ STRI_broad } & & & 0.119 & & & 0.0939 \\
\hline & & & $(0.0907)$ & & & $(0.0782)$ \\
\hline Observations & 353 & 131 & 130 & 353 & 131 & 130 \\
\hline R-squared & 0.288 & 0.282 & 0.277 & 0.112 & 0.182 & 0.158 \\
\hline
\end{tabular}




\title{
Online Appendix to: The Economic Effects of Brexit - Evidence from the Stock Market
}

\author{
Holger Breinlich Elsa Leromain Dennis Novy Thomas Sampson \\ Ahmed Usman
}

August 27, 2018

This appendix provides results from a number of additional robustness checks not reported in the paper: i) including investment trusts in our regression sample; ii) using a narrower definition of our trade barrier measures by using only data for a firm's core industry rather than an average barrier across all industries a firm is active in; iii) including dummy variables for broad NACE 1-digit industry groups (Agriculture and Mining, Manufacturing, Utilities and Construction, Finance and Insurance, and Other Services); iv) using a different market portfolio proxy for the computation of abnormal returns (the MSCI Europe instead of the FTSE All Shares); and v) using a shorter estimation period (six months instead of a one year).

The results in Table A.1 are based on a larger regression sample that also includes investment trusts. This increases our sample size by around $50 \%$ but leaves the results on 24 June 2016 broadly intact. In particular, the recession and sterling depreciation proxies retain their signs and significance although the export status variable is now only statistically significant at the $15 \%$ level. One exception is that the share of EU affiliates is now statistically significant for the full sample in column 1. However, the coefficient magnitude is very similar to Table 5, suggesting that it is the increase in sample size that led to the gain in statistical significance.

The results for the other two event dates are also broadly similar to before. Note that since investment trusts are not in the goods-producing sector, we do not observe MFN tariffs for them, and the results in columns 2,5 and 8 are basically identical to before. ${ }^{1}$ By contrast, the STRI contains a measure of restrictiveness for financial services which is what we use for investment trusts. We acknowledge that the restrictiveness indicated by the STRI might not be relevant for investment trusts who are likely to be less affected by issues such as passporting rights after Brexit. The coefficient estimate on the STRI variable does indeed drop on 17 January 2017 compared to our baseline specification, indicating that measurement error might be a problem.

Table A.2 reports results for our goods and service producing subsamples where we apply a narrower definition of our trade barrier measures by using only data for a firm's core industry rather than an average barrier across all industries a firm is active in. This further reduces sample size, especially for the regressions containing the STRI. Nevertheless, results for both trade barrier variables are very similar to before.

In Table A.3, we include dummy variables for broad NACE 1-digit industry groups (Agriculture and Mining, Manufacturing, Utilities and Construction, Finance and Insurance, and Other Services). Note that we cannot include finer industry fixed effects because some of our key variables only vary at the industry level. As seen, the results are broadly similar to the robustness check of including investment trusts. The recession and depreciation proxies retain their signs and significance, with the export status variable again being less significant and the EU affiliates variable more significant.

\footnotetext{
${ }^{1}$ The small increase in the number of observations from 131 to 133 is due to the fact that we now use the log of a firm's total assets as a proxy for size. While we believe that firm sales are a better indicator, they are not available for investment trusts, hence the switch to total assets.
} 
Finally, in Tables A.4 and A.5, we further examine the robustness of our results to different specifications for the estimation of abnormal returns. In Table A.4 we use a different market portfolio (the MSCI Europe instead of the FTSE All Shares) and in Table A.5 we use a different length for the estimation period (six months instead of a one year). Both modifications again leave the baseline results essentially unchanged. 
Table A.1: Sample with Investment Trusts

\begin{tabular}{|c|c|c|c|c|c|c|c|c|c|}
\hline Date & 24 June 16 & 24 June 16 & 24 June 16 & 5 Oct 16 & 5 Oct 16 & 5 Oct 16 & $17 \operatorname{Jan} 17$ & 17 Jan 17 & 17 Jan 17 \\
\hline & (1) & $(2)$ & (3) & (4) & (5) & (6) & (7) & (8) & (9) \\
\hline VARIABLES & $A R(t)$ & $A R(t)$ & $A R(t)$ & $A R(t)$ & $A R(t)$ & $A R(t)$ & $A R(t)$ & $A R(t)$ & $A R(t)$ \\
\hline \multirow[t]{2}{*}{ ROA } & $-0.0694 * *$ & -0.0480 & -0.0390 & $-0.0257^{* *}$ & -0.0253 & $-0.0248^{*}$ & -0.0138 & -0.0190 & -0.0137 \\
\hline & $(0.0299)$ & $(0.0346)$ & (0.0419) & (0.0109) & $(0.0174)$ & $(0.0148)$ & $(0.00878)$ & $(0.0135)$ & $(0.0126)$ \\
\hline \multirow[t]{2}{*}{ Log(assets) } & -0.00360 & $0.00936 * * *$ & -0.00322 & 0.000306 & $-9.82 e-05$ & 0.000448 & 0.000209 & $-0.00246^{*}$ & $-4.60 e-05$ \\
\hline & (0.00258) & $(0.00339)$ & $(0.00239)$ & $(0.00103)$ & $(0.00172)$ & (0.00119) & $(0.000724)$ & $(0.00133)$ & $(0.000748)$ \\
\hline \multirow[t]{2}{*}{ Non-GBP currency } & $0.0389 * * *$ & $0.0201 *$ & $0.0286^{*}$ & 0.00197 & 0.00390 & -0.00170 & 0.000877 & 0.00596 & 0.00449 \\
\hline & $(0.00877)$ & (0.0110) & $(0.0157)$ & $(0.00389)$ & $(0.00585)$ & $(0.00505)$ & $(0.00246)$ & $(0.00557)$ & $(0.00387)$ \\
\hline \multirow[t]{2}{*}{ Share EU affiliates } & $-0.0358 * *$ & $-0.0727^{* * *}$ & -0.0268 & -0.00427 & 0.00181 & -0.00138 & 0.00510 & -0.00224 & $0.00986 * *$ \\
\hline & $(0.0159)$ & $(0.0262)$ & $(0.0201)$ & $(0.00361)$ & $(0.0145)$ & $(0.00315)$ & $(0.00335)$ & $(0.0107)$ & $(0.00459)$ \\
\hline \multirow[t]{2}{*}{ Share UK affiliates } & $-0.0796 * * *$ & $-0.0749 * * *$ & $-0.0620 * * *$ & -0.00495 & 0.00744 & -0.00521 & $0.0112 * * *$ & 0.0120 & $0.00965^{* * *}$ \\
\hline & $(0.0154)$ & $(0.0267)$ & $(0.0117)$ & $(0.00314)$ & $(0.0113)$ & $(0.00361)$ & $(0.00212)$ & $(0.00802)$ & $(0.00233)$ \\
\hline \multirow[t]{2}{*}{ Log(\# affiliates) } & 0.00160 & -0.00517 & 0.00172 & -0.000474 & 0.00141 & -0.000223 & 0.000720 & 0.00155 & $0.00145^{* *}$ \\
\hline & (0.00279) & $(0.00461)$ & $(0.00380)$ & $(0.000869)$ & $(0.00170)$ & $(0.000981)$ & $(0.000620)$ & $(0.00128)$ & $(0.000718)$ \\
\hline \multirow[t]{2}{*}{ Share EU immigrants } & 0.0404 & -0.0138 & 0.0272 & 0.0148 & 0.00398 & 0.0207 & 0.00358 & 0.00582 & 0.00334 \\
\hline & $(0.0325)$ & (0.0269) & $(0.0536)$ & $(0.0124)$ & (0.0159) & $(0.0191)$ & $(0.00645)$ & $(0.0117)$ & $(0.0146)$ \\
\hline \multirow[t]{2}{*}{ Recession-proof } & $0.0354 * * *$ & $0.0155^{*}$ & $0.0467 * * *$ & -0.00463 & -0.00183 & -0.00355 & $-0.00656 * * *$ & -0.00565 & $-0.0100 * * *$ \\
\hline & $(0.00790)$ & $(0.00852)$ & $(0.0135)$ & $(0.00365)$ & $(0.00317)$ & $(0.00813)$ & $(0.00248)$ & $(0.00351)$ & (0.00349) \\
\hline \multirow[t]{2}{*}{ Exporter } & 0.00871 & 0.00238 & $0.0178^{*}$ & 0.00241 & 0.00766 & -0.00366 & -0.000386 & 0.000937 & -0.000513 \\
\hline & $(0.00563)$ & (0.0111) & (0.0105) & $(0.00233)$ & $(0.00578)$ & $(0.00382)$ & (0.00184) & (0.00330) & $(0.00355)$ \\
\hline \multirow[t]{2}{*}{ Importer } & -0.00452 & -0.00103 & -0.00453 & 0.00446 & $0.0115^{*}$ & -0.00105 & 0.00119 & 0.000759 & -0.00171 \\
\hline & (0.00915) & $(0.0148)$ & (0.0105) & $(0.00336)$ & $(0.00679)$ & $(0.00545)$ & $(0.00180)$ & $(0.00418)$ & $(0.00237)$ \\
\hline \multirow[t]{2}{*}{ Exp.-Importer } & $0.0237^{* *}$ & 0.0171 & 0.0252 & -0.00259 & -0.00698 & 0.00645 & -0.00386 & -0.00335 & 0.00747 \\
\hline & $(0.0106)$ & $(0.0156)$ & $(0.0152)$ & $(0.00430)$ & $(0.00789)$ & $(0.00775)$ & $(0.00442)$ & $(0.00537)$ & $(0.00676)$ \\
\hline \multirow[t]{2}{*}{ EU MFN_broad } & & -0.0266 & & & $-0.0454 * *$ & & & -0.0166 & \\
\hline & & (0.0371) & & & $(0.0202)$ & & & $(0.0131)$ & \\
\hline \multirow[t]{2}{*}{ STRI_broad } & & & 0.0402 & & & 0.00927 & & & -0.0172 \\
\hline & & & (0.0410) & & & $(0.0154)$ & & & $(0.0132)$ \\
\hline \multirow[t]{2}{*}{ Investment trust } & $0.0311^{* * *}$ & & $0.0534^{* * *}$ & 0.00219 & & -0.00188 & $-0.00531 * * *$ & & $-0.00863 * *$ \\
\hline & $(0.0101)$ & & $(0.0151)$ & $(0.00256)$ & & $(0.00432)$ & $(0.00169)$ & & $(0.00387)$ \\
\hline Observations & 519 & 133 & 266 & 520 & 133 & 266 & 520 & 133 & 266 \\
\hline R-squared & 0.385 & 0.386 & 0.422 & 0.056 & 0.136 & 0.048 & 0.110 & 0.152 & 0.186 \\
\hline
\end{tabular}

Notes: Overall sample includes Investment Trusts. The dependent variable in columns (1)-(3) is the abnormal returns on the first trading day following the referendum. The dependent variable in columns (4)-(6) is

the abnormal returns after Theresa May's speech at the Conservative Party conference. The dependent variable in columns (7)-(9) is the abnormal returns after the Lancaster House speech. Columns (1), (4) and (7) estimate the baseline equation for the overall sample. Columns (2), (5) and (8) estimate the baseline equation including the measure of the MFN tariff rate for good-producing industries. Columns (3), (6), and (9) estimate the baseline equation including the measure of NTBs for selected services industries. Robust standard errors in parentheses, clustered at the 4 -digit NACE level. $* * * p<0.01, * * p<0.05, * p<0.1$ 
Table A.2: Narrow Definition of Tariff and Non-Tariff Barriers

\begin{tabular}{|c|c|c|c|c|c|c|}
\hline Date & 24 June 2016 & 24 June 2016 & 5 Oct 2016 & 5 Oct 2016 & 17 Jan 2017 & 17 Jan 2017 \\
\hline & (1) & $(2)$ & (3) & (4) & (5) & (6) \\
\hline VARIABLES & $A R(t)$ & $A R(t)$ & $A R(t)$ & $A R(t)$ & $A R(t)$ & $A R(t)$ \\
\hline \multirow[t]{2}{*}{ ROA } & -0.0553 & 0.0202 & -0.0251 & $-0.0280 *$ & -0.0132 & 0.000891 \\
\hline & $(0.0446)$ & $(0.0893)$ & $(0.0169)$ & $(0.0149)$ & $(0.0133)$ & $(0.0207)$ \\
\hline \multirow[t]{2}{*}{ Log(sales) } & $0.00811 * *$ & -0.00291 & -0.000365 & $0.00302 * *$ & $-0.00227^{*}$ & 0.000596 \\
\hline & (0.00349) & $(0.00343)$ & $(0.00173)$ & $(0.00129)$ & $(0.00128)$ & $(0.00136)$ \\
\hline \multirow[t]{2}{*}{ Non-GBP currency } & $0.0250 * *$ & $0.0463 *$ & 0.00399 & 0.00487 & 0.00396 & -0.00674 \\
\hline & $(0.0115)$ & $(0.0235)$ & $(0.00602)$ & $(0.00498)$ & $(0.00545)$ & $(0.00523)$ \\
\hline \multirow[t]{2}{*}{ Share EU affiliates } & $-0.0755^{* * *}$ & -0.109 & 0.00310 & -0.00772 & -0.00354 & 0.0163 \\
\hline & $(0.0276)$ & $(0.0728)$ & $(0.0148)$ & $(0.0157)$ & $(0.0112)$ & $(0.0151)$ \\
\hline \multirow[t]{2}{*}{ Share UK affiliates } & $-0.0785^{* * *}$ & $-0.0651 * *$ & 0.00933 & $0.0143^{*}$ & 0.0106 & $9.61 e-05$ \\
\hline & $(0.0280)$ & $(0.0244)$ & $(0.0118)$ & $(0.00811)$ & $(0.00823)$ & $(0.0113)$ \\
\hline \multirow[t]{2}{*}{ Log(\# affiliates) } & -0.00381 & 0.00471 & 0.00201 & -0.00121 & 0.00174 & 0.00229 \\
\hline & $(0.00522)$ & $(0.00730)$ & $(0.00201)$ & $(0.00139)$ & $(0.00158)$ & $(0.00237)$ \\
\hline \multirow[t]{2}{*}{ Share EU immigrants } & -0.0319 & -0.120 & 0.00231 & 0.0572 & 0.00937 & -0.0187 \\
\hline & $(0.0244)$ & $(0.133)$ & $(0.0155)$ & $(0.0597)$ & $(0.0122)$ & $(0.0421)$ \\
\hline \multirow[t]{2}{*}{ Recession-proof } & $0.0192 * *$ & $0.0544 * * *$ & -0.00190 & 0.00600 & $-0.00707^{* *}$ & $-0.0158 * * *$ \\
\hline & $(0.00791)$ & $(0.0185)$ & $(0.00334)$ & $(0.0144)$ & $(0.00342)$ & $(0.00538)$ \\
\hline \multirow[t]{2}{*}{ Exporter } & -0.000752 & $0.0303^{*}$ & 0.00748 & 0.000373 & 0.000636 & $-0.00838^{*}$ \\
\hline & (0.0119) & (0.0159) & $(0.00592)$ & $(0.00493)$ & $(0.00386)$ & $(0.00487)$ \\
\hline \multirow[t]{2}{*}{ Importer } & -0.00774 & -0.000478 & 0.0112 & 0.00410 & 0.000865 & $-0.00809 * * *$ \\
\hline & $(0.0146)$ & $(0.0153)$ & $(0.00713)$ & $(0.00882)$ & $(0.00460)$ & $(0.00267)$ \\
\hline \multirow[t]{2}{*}{ Exp.-Importer } & 0.0246 & 0.0158 & -0.00692 & -0.00341 & -0.00478 & $0.0262 * *$ \\
\hline & $(0.0151)$ & $(0.0271)$ & $(0.00840)$ & $(0.0208)$ & $(0.00576)$ & $(0.0105)$ \\
\hline \multirow[t]{2}{*}{ EU MFN_narrow } & -0.0204 & & $-0.0482 * *$ & & -0.0116 & \\
\hline & $(0.0391)$ & & $(0.0225)$ & & $(0.0153)$ & \\
\hline \multirow[t]{2}{*}{ STRI_narrow } & & 0.0714 & & 0.00285 & & $-0.0268 * *$ \\
\hline & & $(0.0685)$ & & $(0.0204)$ & & (0.0119) \\
\hline Observations & 126 & 78 & 126 & 78 & 126 & 78 \\
\hline R-squared & 0.401 & 0.327 & 0.138 & 0.157 & 0.140 & 0.234 \\
\hline
\end{tabular}

Notes: The dependent variable in columns (1)-(3) is the abnormal returns on the first trading day following the referendum. The dependent variable in columns (4)-(6) is the abnormal returns after Theresa May's
speech at the Conservative Party conference. The dependent variable in columns (7)-(9) is the abnormal returns after the Lancaster House speech. Columns (1), (4) and (7) estimate the baseline equation for the overall sample. Columns (2), (5) and (8) estimate the baseline equation including the narrower measure of the MFN tariff rate for good-producing industries. Columns (3), (6), and (9) estimate the baseline equation including the narrower measure of NTBs for selected services industries. Robust standard errors in parentheses, clustered at the 4 -digit NACE level. ${ }^{* * *} p<0.01, * * p<0.05, * p<0.1$ 
Table A.3: Industry Group Dummies

\begin{tabular}{|c|c|c|c|c|c|c|c|c|c|}
\hline Date & 24 June 16 & 24 June 16 & 24 June 16 & 5 Oct 16 & 5 Oct 16 & 5 Oct 16 & 17 Jan 17 & 17 Jan 17 & $17 \operatorname{Jan} 17$ \\
\hline & (1) & (2) & (3) & (4) & (5) & (6) & (7) & (8) & (9) \\
\hline VARIABLES & $A R(t)$ & $A R(t)$ & $A R(t)$ & $A R(t)$ & $A R(t)$ & $A R(t)$ & $A R(t)$ & $A R(t)$ & $A R(t)$ \\
\hline \multirow[t]{2}{*}{ ROA } & $-0.0577^{*}$ & -0.0558 & -0.0462 & $-0.0277 * *$ & $-0.0242 *$ & $-0.0332 * *$ & -0.0109 & -0.0130 & 0.00357 \\
\hline & $(0.0332)$ & $(0.0472)$ & $(0.0755)$ & $(0.0118)$ & $(0.0128)$ & $(0.0158)$ & $(0.0100)$ & $(0.0128)$ & $(0.0208)$ \\
\hline \multirow[t]{2}{*}{ Log(sales) } & 0.00176 & $0.00737 * *$ & 0.000267 & 0.00101 & -0.000467 & $0.00293 * *$ & -0.000557 & -0.00211 & -0.000314 \\
\hline & (0.00229) & $(0.00316)$ & $(0.00415)$ & $(0.000787)$ & $(0.00158)$ & $(0.00112)$ & $(0.000754)$ & $(0.00142)$ & $(0.00127)$ \\
\hline \multirow[t]{2}{*}{ Non-GBP currency } & $0.0277 * * *$ & $0.0321 * * *$ & 0.0178 & 0.00136 & -0.00299 & 0.000951 & -0.00189 & -0.000462 & -0.00207 \\
\hline & $(0.00873)$ & $(0.00957)$ & $(0.0224)$ & $(0.00422)$ & $(0.00878)$ & $(0.00398)$ & $(0.00254)$ & $(0.00491)$ & (0.00447) \\
\hline \multirow[t]{2}{*}{ Share EU affiliates } & $-0.0615^{* *}$ & $-0.0731 * * *$ & -0.0662 & -0.000296 & 0.00195 & -0.00197 & 0.00667 & -0.00333 & $0.0200 *$ \\
\hline & $(0.0257)$ & $(0.0266)$ & $(0.0758)$ & $(0.00682)$ & $(0.0141)$ & $(0.0116)$ & $(0.00590)$ & $(0.0108)$ & $(0.0113)$ \\
\hline \multirow[t]{2}{*}{ Share UK affiliates } & $-0.0928 * * *$ & $-0.0789 * * *$ & $-0.0957 * * *$ & 0.00647 & 0.00902 & 0.0110 & $0.0119 * * *$ & $0.0128^{*}$ & 0.00692 \\
\hline & $(0.0140)$ & $(0.0261)$ & $(0.0272)$ & $(0.00462)$ & $(0.0116)$ & $(0.00669)$ & $(0.00377)$ & $(0.00755)$ & $(0.00906)$ \\
\hline \multirow{2}{*}{ Log(\# affiliates) } & -0.000291 & -0.00363 & -0.00187 & -0.000560 & 0.00214 & -0.00106 & 0.000642 & 0.00170 & 0.00104 \\
\hline & $(0.00337)$ & $(0.00445)$ & $(0.00692)$ & $(0.000920)$ & $(0.00200)$ & $(0.00135)$ & $(0.000929)$ & $(0.00167)$ & $(0.00164)$ \\
\hline \multirow[t]{2}{*}{ Share EU immigrants } & 0.00159 & -0.0213 & -0.0353 & 0.00348 & 0.000810 & 0.000763 & 0.00321 & 0.00565 & 0.0134 \\
\hline & (0.0309) & $(0.0248)$ & $(0.0788)$ & $(0.0145)$ & $(0.0142)$ & $(0.0244)$ & $(0.00926)$ & $(0.0126)$ & $(0.0205)$ \\
\hline \multirow[t]{2}{*}{ Recession-proof } & $0.0328 * * *$ & $0.0205^{* *}$ & $0.0492 * * *$ & -0.00222 & -0.000572 & -0.00353 & $-0.00499 *$ & -0.00595 & $-0.00828 * *$ \\
\hline & $(0.00732)$ & $(0.00784)$ & $(0.0153)$ & $(0.00373)$ & $(0.00430)$ & $(0.00750)$ & $(0.00274)$ & $(0.00370)$ & $(0.00411)$ \\
\hline \multirow[t]{2}{*}{ Exporter } & 0.00617 & 0.00243 & 0.0189 & $0.00485^{*}$ & 0.00679 & $-3.78 e-05$ & -0.000497 & 0.000592 & -0.00195 \\
\hline & $(0.00756)$ & $(0.0113)$ & $(0.0138)$ & $(0.00272)$ & $(0.00530)$ & $(0.00408)$ & $(0.00245)$ & $(0.00355)$ & $(0.00425)$ \\
\hline \multirow[t]{2}{*}{ Importer } & -0.00274 & -0.00468 & -0.00126 & $0.00636 *$ & 0.0104 & 0.00230 & $1.42 \mathrm{e}-05$ & 0.000227 & -0.00209 \\
\hline & (0.00779) & $(0.0140)$ & $(0.0120)$ & $(0.00364)$ & $(0.00696)$ & $(0.00609)$ & $(0.00184)$ & $(0.00442)$ & (0.00291) \\
\hline \multirow[t]{2}{*}{ Exp.-Importer } & $0.0255^{* *}$ & 0.0213 & 0.0274 & -0.00329 & -0.00537 & 0.000724 & -0.00326 & -0.00362 & 0.0105 \\
\hline & $(0.0100)$ & $(0.0146)$ & $(0.0201)$ & $(0.00502)$ & $(0.00772)$ & $(0.0101)$ & $(0.00481)$ & $(0.00572)$ & (0.00795) \\
\hline \multirow[t]{2}{*}{ EU MFN_broad } & & -0.0203 & & & $-0.0456 * *$ & & & -0.0149 & \\
\hline & & $(0.0397)$ & & & $(0.0202)$ & & & $(0.0157)$ & \\
\hline \multirow[t]{2}{*}{ STRI_broad } & & & 0.0423 & & & 0.00190 & & & -0.00777 \\
\hline & & & $(0.0472)$ & & & $(0.0157)$ & & & $(0.0158)$ \\
\hline Observations & 352 & 131 & 130 & 353 & 131 & 130 & 353 & 131 & 130 \\
\hline R-squared & 0.417 & 0.410 & 0.387 & 0.103 & 0.172 & 0.178 & 0.113 & 0.164 & 0.181 \\
\hline
\end{tabular}
speech at the Conservative Party conference. The dependent variable in columns (7)-(9) is the abnormal returns after the Lancaster House speech. Estimations includes a dummy variable for broad NACE 1-digit industries. Columns (1), (4) and (7) estimate the baseline equation for the overall sample. Columns (2), (5) and (8) estimate the baseline equation including the measure of the MFN tariff rate for good-producing industries. Columns (3), (6), and (9) estimate the baseline equation including the measure of NTBs for selected services industries. Robust standard errors in parentheses, clustered at the 4-digit NACE level.

*** $\mathrm{p}<0.01, * * \mathrm{p}<0.05, * \mathrm{p}<0.1$ 
Table A.4: Different Market Portfolio (MSCl Europe)

\begin{tabular}{|c|c|c|c|c|c|c|c|c|c|}
\hline Date & 24 June 16 & 24 June 16 & 24 June 16 & 5 Oct 16 & 5 Oct 16 & 5 Oct 16 & 17 Jan 17 & 17 Jan 17 & 17 Jan 17 \\
\hline & (1) & $(2)$ & (3) & (4) & (5) & (6) & (7) & (8) & (9) \\
\hline VARIABLES & $A R(t)$ & $A R(t)$ & $A R(t)$ & $A R(t)$ & $A R(t)$ & $A R(t)$ & $A R(t)$ & $A R(t)$ & $A R(t)$ \\
\hline \multirow[t]{2}{*}{ ROA } & $-0.0952 * *$ & $-0.120 * * *$ & -0.0910 & $-0.0254 * *$ & -0.0180 & $-0.0351 * *$ & 0.00119 & 0.0137 & 0.0141 \\
\hline & $(0.0365)$ & $(0.0443)$ & (0.0901) & $(0.0127)$ & (0.0159) & $(0.0155)$ & (0.00973) & (0.0139) & (0.0177) \\
\hline \multirow[t]{2}{*}{ Log(sales) } & $0.00577 * * *$ & $0.0138 * * *$ & 0.00205 & 0.000421 & -0.00110 & $0.00207^{*}$ & $-0.00253 * * *$ & $-0.00508 * * *$ & -0.00190 \\
\hline & $(0.00207)$ & $(0.00345)$ & $(0.00405)$ & $(0.000743)$ & (0.00159) & $(0.00116)$ & $(0.000796)$ & $(0.00142)$ & $(0.00124)$ \\
\hline \multirow[t]{2}{*}{ Non-GBP currency } & $0.0468 * * *$ & $0.0328 * *$ & $0.0357 *$ & 0.00458 & 0.00337 & 0.00390 & -0.00408 & 0.00106 & -0.000669 \\
\hline & $(0.00952)$ & $(0.0126)$ & $(0.0212)$ & $(0.00344)$ & $(0.00555)$ & $(0.00437)$ & $(0.00264)$ & $(0.00549)$ & $(0.00455)$ \\
\hline \multirow[t]{2}{*}{ Share EU affiliates } & $-0.0529 *$ & $-0.0805^{* * *}$ & -0.0514 & 0.00106 & 0.00254 & -0.00129 & 0.00866 & -0.000864 & 0.0172 \\
\hline & $(0.0272)$ & $(0.0271)$ & (0.0794) & $(0.00660)$ & (0.0146) & $(0.0108)$ & $(0.00612)$ & (0.0109) & (0.0118) \\
\hline \multirow[t]{2}{*}{ Share UK affiliates } & $-0.0980 * * *$ & $-0.0872 * * *$ & $-0.0973 * * *$ & 0.00647 & 0.00838 & 0.00880 & $0.0137^{* * *}$ & $0.0154^{* *}$ & 0.00914 \\
\hline & $(0.0163)$ & $(0.0267)$ & (0.0303) & $(0.00471)$ & $(0.0110)$ & $(0.00688)$ & $(0.00416)$ & $(0.00725)$ & $(0.00831)$ \\
\hline \multirow[t]{2}{*}{ Log(\# affiliates) } & -0.00144 & -0.00517 & -0.00119 & -0.000603 & 0.00172 & -0.00116 & 0.000531 & 0.00194 & 0.00109 \\
\hline & (0.00294) & $(0.00468)$ & $(0.00660)$ & $(0.000830)$ & $(0.00180)$ & $(0.00126)$ & (0.000950) & $(0.00151)$ & $(0.00157)$ \\
\hline \multirow[t]{2}{*}{ Share EU immigrants } & 0.00616 & -0.0319 & -0.00614 & 0.00371 & 0.00418 & -0.00883 & 0.00595 & 0.00892 & 0.00297 \\
\hline & $(0.0341)$ & $(0.0285)$ & $(0.0807)$ & $(0.0132)$ & (0.0147) & $(0.0214)$ & $(0.00854)$ & (0.0128) & (0.0219) \\
\hline \multirow[t]{2}{*}{ Recession-proof } & $0.0250 * * *$ & 0.00828 & $0.0506 * * *$ & -0.00304 & -0.00106 & -0.00472 & -0.00228 & -0.00304 & -0.00669 \\
\hline & $(0.00795)$ & $(0.00867)$ & $(0.0136)$ & $(0.00348)$ & $(0.00306)$ & $(0.00816)$ & $(0.00255)$ & $(0.00360)$ & $(0.00481)$ \\
\hline \multirow[t]{2}{*}{ Exporter } & $0.0136 * *$ & 0.00255 & $0.0262 *$ & $0.00581 * *$ & 0.00735 & 0.00254 & -0.000380 & 0.000134 & 0.000437 \\
\hline & $(0.00686)$ & (0.0102) & $(0.0141)$ & $(0.00231)$ & $(0.00528)$ & $(0.00431)$ & $(0.00215)$ & $(0.00374)$ & $(0.00422)$ \\
\hline \multirow[t]{2}{*}{ Importer } & 0.00193 & 0.00329 & 0.00233 & $0.00686 * *$ & 0.0102 & 0.00416 & -0.00103 & -0.00396 & -0.00241 \\
\hline & $(0.00863)$ & (0.0137) & (0.0128) & $(0.00347)$ & $(0.00661)$ & $(0.00607)$ & (0.00207) & (0.00549) & $(0.00270)$ \\
\hline \multirow[t]{2}{*}{ Exp.-Importer } & $0.0206^{*}$ & 0.0172 & 0.0174 & -0.00500 & -0.00609 & -0.00417 & -0.00251 & -0.00134 & 0.00815 \\
\hline & (0.0109) & (0.0155) & $(0.0180)$ & (0.00490) & $(0.00789)$ & (0.00989) & $(0.00484)$ & (0.00650) & $(0.00768)$ \\
\hline \multirow[t]{2}{*}{ EU MFN_broad } & & -0.0491 & & & $-0.0402 * *$ & & & 0.00143 & \\
\hline & & $(0.0377)$ & & & (0.0199) & & & $(0.0157)$ & \\
\hline \multirow[t]{2}{*}{ STRI_broad } & & & 0.0546 & & & 0.00506 & & & -0.0120 \\
\hline & & & (0.0499) & & & $(0.0174)$ & & & $(0.0123)$ \\
\hline Observations & 352 & 131 & 130 & 353 & 131 & 130 & 353 & 131 & 130 \\
\hline R-squared & 0.428 & 0.518 & 0.361 & 0.061 & 0.119 & 0.078 & 0.159 & 0.289 & 0.112 \\
\hline
\end{tabular}


Table A.5: Baseline Results with Abnormal Return Estimates Based on Six-Month Estimation Period

\begin{tabular}{|c|c|c|c|c|c|c|c|c|c|}
\hline Date & 24 June 16 & 24 June 16 & 24 June 16 & 5 Oct 16 & 5 Oct 16 & 5 Oct 16 & 17 Jan 17 & 17 Jan 17 & 17 Jan 17 \\
\hline & (1) & $(2)$ & (3) & (4) & (5) & (6) & (7) & (8) & (9) \\
\hline VARIABLES & $A R(t)$ & $A R(t)$ & $A R(t)$ & $A R(t)$ & $A R(t)$ & $A R(t)$ & $A R(t)$ & $A R(t)$ & $A R(t)$ \\
\hline \multirow[t]{2}{*}{ ROA } & -0.0520 & -0.0467 & -0.0477 & -0.0232 & -0.0154 & $-0.0367 * *$ & -0.00836 & -0.00434 & -0.00132 \\
\hline & $(0.0350)$ & $(0.0455)$ & $(0.0853)$ & $(0.0144)$ & (0.0195) & $(0.0162)$ & $(0.0109)$ & (0.0139) & $(0.0204)$ \\
\hline \multirow[t]{2}{*}{ Log(sales) } & 0.00211 & $0.00829 * *$ & -0.000609 & 0.000935 & -0.000370 & $0.00260 * *$ & -0.000431 & -0.00207 & -0.000118 \\
\hline & $(0.00202)$ & $(0.00325)$ & $(0.00392)$ & $(0.000770)$ & $(0.00175)$ & $(0.00123)$ & $(0.000795)$ & $(0.00129)$ & $(0.00140)$ \\
\hline \multirow[t]{2}{*}{ Non-GBP currency } & $0.0346 * * *$ & $0.0229 * *$ & 0.0295 & 0.00488 & 0.00276 & 0.00492 & $3.26 e-05$ & 0.00261 & 0.00312 \\
\hline & $(0.00768)$ & (0.00995) & $(0.0207)$ & (0.00394) & $(0.00620)$ & $(0.00450)$ & $(0.00311)$ & $(0.00544)$ & $(0.00536)$ \\
\hline \multirow[t]{2}{*}{ Share EU affiliates } & $-0.0448 *$ & $-0.0724 * * *$ & -0.0464 & 0.000305 & 0.00369 & -0.00188 & 0.00391 & -0.00162 & 0.0144 \\
\hline & $(0.0260)$ & $(0.0252)$ & $(0.0785)$ & $(0.00704)$ & (0.0159) & $(0.0110)$ & $(0.00674)$ & $(0.0122)$ & $(0.0119)$ \\
\hline \multirow[t]{2}{*}{ Share UK affiliates } & $-0.0921 * * *$ & $-0.0754 * * *$ & $-0.0902 * * *$ & 0.00701 & 0.00973 & 0.00973 & $0.0133 * * *$ & $0.0143^{*}$ & 0.00973 \\
\hline & $(0.0153)$ & $(0.0256)$ & (0.0299) & (0.00489) & $(0.0116)$ & $(0.00719)$ & $(0.00440)$ & $(0.00832)$ & (0.00945) \\
\hline \multirow[t]{2}{*}{ Log(\# affiliates) } & -0.00186 & -0.00401 & -0.00162 & -0.000367 & 0.00171 & -0.000983 & 0.00103 & 0.00151 & 0.00156 \\
\hline & $(0.00277)$ & $(0.00469)$ & $(0.00633)$ & $(0.000855)$ & $(0.00193)$ & $(0.00134)$ & $(0.000965)$ & $(0.00153)$ & $(0.00174)$ \\
\hline \multirow[t]{2}{*}{ Share EU immigrants } & 0.0122 & -0.0331 & -0.000830 & 0.00289 & 0.00407 & -0.00814 & 0.00129 & 0.00689 & 0.000618 \\
\hline & $(0.0311)$ & $(0.0217)$ & $(0.0770)$ & $(0.0141)$ & $(0.0161)$ & $(0.0218)$ & $(0.00944)$ & $(0.0128)$ & $(0.0241)$ \\
\hline \multirow[t]{2}{*}{ Recession-proof } & $0.0324 * * *$ & $0.0181^{* *}$ & $0.0537 * * *$ & -0.00413 & -0.00133 & -0.00702 & $-0.00702 * *$ & $-0.00648 *$ & $-0.0135 * * *$ \\
\hline & $(0.00744)$ & $(0.00724)$ & $(0.0135)$ & (0.00359) & $(0.00332)$ & $(0.00823)$ & $(0.00280)$ & $(0.00354)$ & (0.00507) \\
\hline \multirow[t]{2}{*}{ Exporter } & $0.0141 * *$ & 0.00250 & $0.0298 * *$ & $0.00579 * *$ & 0.00812 & 0.00157 & -0.000429 & 0.00195 & -0.00280 \\
\hline & $(0.00672)$ & $(0.0103)$ & $(0.0138)$ & $(0.00242)$ & $(0.00587)$ & $(0.00441)$ & $(0.00221)$ & $(0.00376)$ & $(0.00434)$ \\
\hline \multirow[t]{2}{*}{ Importer } & -0.000853 & -0.00674 & 0.00478 & $0.00732 * *$ & 0.0114 & 0.00349 & 0.000813 & 0.00102 & -0.00437 \\
\hline & (0.00799) & (0.0139) & (0.0119) & $(0.00347)$ & $(0.00697)$ & $(0.00597)$ & $(0.00192)$ & $(0.00449)$ & (0.00285) \\
\hline \multirow[t]{2}{*}{ Exp.-Importer } & $0.0210 * *$ & 0.0225 & 0.0135 & -0.00564 & -0.00702 & -0.00370 & -0.00444 & -0.00492 & 0.0108 \\
\hline & (0.00979) & $(0.0145)$ & $(0.0173)$ & $(0.00505)$ & $(0.00842)$ & $(0.00977)$ & (0.00499) & $(0.00594)$ & (0.00794) \\
\hline \multirow[t]{2}{*}{ EU MFN_broad } & & -0.0280 & & & $-0.0440 *$ & & & -0.0135 & \\
\hline & & $(0.0340)$ & & & $(0.0223)$ & & & $(0.0166)$ & \\
\hline \multirow[t]{2}{*}{ STRI_broad } & & & 0.0776 & & & 0.000705 & & & $-0.0264^{*}$ \\
\hline & & & $(0.0472)$ & & & $(0.0176)$ & & & $(0.0135)$ \\
\hline Observations & 352 & 131 & 130 & 353 & 131 & 130 & 353 & 131 & 130 \\
\hline R-squared & 0.366 & 0.390 & 0.329 & 0.062 & 0.114 & 0.096 & 0.081 & 0.137 & 0.115 \\
\hline
\end{tabular}




\section{CENTRE FOR ECONOMIC PERFORMANCE \\ Recent Discussion Papers}

1569

J. Vernon Henderson

Sebastian Kriticos

Dzhamilya Nigmatulina

1568 Philippe Bracke

Silvana Tenreyro

1567 Ester Faia

Sebastien Laffitte

Gianmarco Ottaviano

1566 Brian Bell

Rui Costa

Stephen Machin

1565 Richard Murphy

Felix Weinhardt

Gill Wyness

1564 Paola Conconi

Giovanni Facchini

Max F. Steinhardt

Maurizio Zanardi

1563 Stephen Gibbons

Stephan Heblich

Ted Pinchbeck

1562

Helen Johnson

Sandra McNally

Heather Rolfe

Jenifer Ruiz-Valenzuela,

Robert Savage

Janet Vousden

Clare Wood

1561
Measuring Urban Economic Density

History Dependence in the Housing Market

Foreign Expansion, Competition and Bank Risk

Why Does Education Reduce Crime?

Who Teaches the Teachers? A RCT of Peerto-Peer Observation and Feedback in 181 Schools

The Political Economy of Trade and Migration: Evidence from the U.S. Congress

The Spatial Impacts of a Massive Rail Disinvestment Program: The Beeching Axe

Teaching Assistants, Computers and Classroom Management: Evidence from a Randomised Control Trial
Quantifying Wide Economic Impacts of Agglomeration for Transport Appraisal: Existing Evidence and Future Directions 
1559 Alan Manning Paolo Masella

1558 Jan David Bakker Stephan Maurer Jörn-Steffen Pischke Ferdinand Rauch

1557 Giuseppe Berlingieri Sara Calligaris

Chiara Criscuolo

1556 Christian A.L. Hilber Olivier Schöni

1555 Filippo Di Mauro

Fadi Hassan

Gianmarco I.P. Ottaviano

1554 Keith Head Yao Amber Li Asier Minondo

1553 Nicholas Bloom

Kalina Manova

Stephen Teng Sun John Van Reenen Zhihong Yu

1552 Gabriel M. Ahlfeldt Wolfgang Maennig Steffen Q. Mueller

1551 Keith Head Tierry Mayer
Market Potential and Global Growth over the Long Twentieth Century

Diffusion of Social Values through the Lens of US Newspapers

Of Mice and Merchants: Trade and Growth in the Iron Age

The Productivity-Wage Premium: Does Size Still Matter in a Service Economy?

The Economic Impacts of Constraining Second Home Investments

Financial Markets and the Allocation of Capital: The Role of Productivity

Geography, Ties and Knowledge Flows: Evidence from Citations in Mathematics

Managing Trade: Evidence from China and the US

The Generation Gap in Direct Democracy

Brands in Motion: How Frictions Shape Multinational Production 